\title{
Elevated Lipoprotein(a): Background, Current Insights and Future Potential Therapies
}

\author{
Ahmed Handhle \\ Adie Viljoen $\mathbb{D}^{2}$ \\ Anthony S Wierzbicki $\mathbb{D}^{3}$ \\ 'Department of Metabolic Medicine/ \\ Chemical Pathology, Addenbrookes \\ Hospital, Cambridge, UK; ${ }^{2}$ Department \\ of Metabolic Medicine/Chemical \\ Pathology, North \& East Hertfordshire \\ Hospitals Trust, Lister Hospital, \\ Hertfordshire, UK; ${ }^{3}$ Department of \\ Metabolic Medicine/Chemical Pathology, \\ Guy's \& St Thomas', Hospitals, London, \\ SEI 7EH, UK
}

\begin{abstract}
Lipoprotein(a) forms a subfraction of the lipid profile and is characterized by the addition of apolipprotein(a) (apo(a)) to apoB100 derived particles. Its levels are mostly genetically determined inversely related to the number of protein domain (kringle) repeats in apo(a). In epidemiological studies, it shows consistent association with cardiovascular disease (CVD) and most recently with extent of aortic stenosis. Issues with standardizing the measurement of $\mathrm{Lp}(\mathrm{a})$ are being resolved and consensus statements favor its measurement in patients at high risk of, or with family histories of CVD events. Major lipid-lowering therapies such as statin, fibrates, and ezetimibe have little effect on Lp(a) levels. Therapies such as niacin or cholesterol ester transfer protein (CETP) inhibitors lower Lp(a) as well as reducing other lipid-related risk factors but have failed to clearly reduce CVD events. Proprotein convertase subtilisin kexin-9 (PCSK9) inhibitors reduce cholesterol and Lp(a) as well as reducing CVD events. New antisense therapies specifically targeting apo(a) and hence $\mathrm{Lp}(\mathrm{a})$ have greater and more specific effects and will help clarify the extent to which intervention in Lp(a) levels will reduce CVD events.
\end{abstract}

Keywords: lipoprotein (a), cardiovascular disease, aortic stenosis, apheresis, genetics, lipoprotein turnover, statin, PCSK9, antisense therapy

\section{Plain Language Summary}

Lipoprotein (a) (Lp(a)) forms a small fraction of cholesterol profile. It is related to the bad cholesterol (low-density-lipoprotein cholesterol; LDL-C) that drives artery narrowing (atherosclerosis) and hence heart attacks, strokes, and large artery disease. It differs from LDL in having an additional protein - apolipoprotein(a) bonded to the particle. This addition changes both the secretion rate and clearance of these particles. Lp(a) levels are mostly inherited with the variation driven by a number of repeats within the apo(a) molecule. The standard treatments for lowering LDL-C such as statins or ezetimibe have little effect on Lp(a) levels. Niacin and proprotein convertase subtilisin kexin-9 (PCSK9) inhibitors reduce Lp(a) but affect other fractions such as LDL-C as well. New specific inhibitors for Lp(a) have been developed and are in early trials.

\section{Introduction}

A standard lipid profile consists of triglyceride-rich particles (especially postprandially) and cholesterol-rich particles involved in transportation of lipids to body compartments (low-density lipoprotein; LDL) and those involved in transporting cholesterol back to the liver for disposal through the biliary system (high density lipoprotein; HDL). While these components are responsible for most of the plasma-related risk for cardiovascular disease (CVD) risk, other factors
Correspondence: Anthony S Wierzbick Metabolic Medicine/Chemical Pathology, St Thomas Hospital, Lambeth Palace Road, London, SEI 7EH, UK

Tel +44 207 I88 I256

Email Anthony.Wierzbicki@kcl.ac.Uk 
contribute including inflammation-related markers (eg, C-reactive protein), coagulation components (eg, fibrinogen or plasminogen), and lipid subfractions. These lipid subfractions include modifications to particle size distribution induced by insulin resistance (eg, small dense LDL) while a small proportion of both triglyceride-rich and LDL particles are distinguished by the covalent addition of apolipoprotein (a) (apo(a)) to $\mathrm{apoB}_{100}$ in an LDL-derived particle.

\section{Structure and Genetics}

Lp (a) is composed of a single apolipoprotein $\mathrm{B}_{100}$ $\left(a p o B_{100}\right)$, covalently linked by a disulfide bond to a single apolipoprotein(a) (apo(a)) allied with associated cholesterol, triglyceride and phospholipid. ${ }^{1-3}$ Apo(a) is encoded by the LPA gene located on chromosome 6q2627 , bears homology to plasminogen and is expressed in hepatocytes. Whereas plasminogen contains 5 kringle (K-I to K-V) and a protease domain, apo(a) contains 10 kringle-IV subtypes $\left(\mathrm{KIV}_{1-10}\right)$. Its molecular mass varies between $275-800 \mathrm{kDa}$ due to the more than 40 allelic LPA variants $^{4-6}$ with wide differences between ethnic groups. ${ }^{7}$ Whilst a single copy each of $\mathrm{K}-\mathrm{IV}_{1}$ and $\mathrm{K}-\mathrm{IV}_{3-10}$ are present, the number of $\mathrm{K}-\mathrm{IV}_{2}$ copies can range from 1 to more than $40 .{ }^{8}$ Variable glycosylation of K-IV motifs and linker sequences that join individual kringles also contribute to this heterogeneity. ${ }^{9}$ Genetic studies have established that serum $L p(a)$ levels are predominantly genetically inherited in an autosomal co-dominant manner $^{2,4}$ and that the allelic variation of the LPA gene is responsible for the large range (up to 1000-fold) seen in $\mathrm{Lp}$ (a) concentrations with concentrations inversely related to the number of $\mathrm{KIV}_{2}$ repeats. ${ }^{8}$ These repeats are too large and too varied to be clearly differentiated by next generation sequencing techniques with current reading depths. A pentanucleotide ${ }^{10}$ and 2 single nucleotide polymorphisms (rs10455872 and rs3798220) predict higher $\mathrm{Lp}$ (a) concentrations ${ }^{11,12}$ and the risk of premature CVD. ${ }^{13,14}$ An intra-genic risk score based on single nucleotide polymorphisms can be used to approximate $\mathrm{Lp}$ (a) concentrations and has similar predictive power to Lp(a) levels. ${ }^{15}$

Proteomic analysis has been conducted for $\mathrm{Lp}$ (a) particles and shows profound differences from LDL particles. ${ }^{16}$ In the first analysis 9 proteins were associated with LDL and 31 with $\mathrm{Lp}$ (a). 15 proteins were confirmed to be associated with $\mathrm{Lp}(\mathrm{a})$. These proteins were involved in negative regulation of peptidase activity, regulation or transport of insulin growth factors, extracellular structure organization, protein processing and binding. ${ }^{16}$ Proteins such as transthyretin, vitronectin, paraoxonase-1 and protease inhibitors might be preferentially transported by $\mathrm{Lp}(\mathrm{a})$. It is interesting that the genetic study suggesting an interaction of $\mathrm{Lp}$ (a) with apoH was not reproduced in this study. ${ }^{17}$

\section{Assembly and Metabolism of Lp(a)}

The site of Lp (a) assembly is unknown and may occur in hepatocytes, extracellularly in the space of Disse or in the plasma. ${ }^{18-20} \mathrm{Lp}(\mathrm{a})$ is mostly assembled by addition of apo(a) to a newly synthesized LDL particle rather than added to a triglyceride-rich very low-density lipoprotein (VLDL) precursor particle. This assembly is accomplished by forming a covalent disulfide bond between $\mathrm{K}-\mathrm{IV}_{9}$ of apo(a) and apoB $_{100}$ of the LDL. In plasma, Lp(a) exists in 3 subfractions - a triglyceride-rich fraction in VLDL, an apoE-rich apoB-containing particle, and a predominant apoB-containing particle. ${ }^{21}$ (figure 1). The major ApoE polymorphism seems to affect the amount of $L p(a)$ with apoE4/E4 resulting in a $65 \%$ higher level than apoE2/E2. ${ }^{22}$

The mechanism of $L p(a)$ clearance from the plasma has not been fully elucidated. ${ }^{23}$ The attachment point for apo(a) is close to the LDL Receptor (LDLR) binding site on apo-B and thus interferes with binding to LDLR leading to reduced clearance and longer plasma half-life of Lp(a) compared to LDL-C. However, LDLR function may be relevant to the clearance of $L p(a)$ as patients with familial hypercholesterolemia (FH) have higher $\mathrm{Lp}(\mathrm{a})$ levels than their unaffected siblings with the effect being dependent on allele dose. Other undefined clearance mechanisms (eg, proteolytic cleavage of apo(a), scavenger receptors including B1 and plasminogen receptors) probably exist for $\mathrm{Lp}(\mathrm{a}){ }^{23,24}$

$\mathrm{Lp}(\mathrm{a})$ is thought to promote atherosclerosis by two main mechanisms. ${ }^{25,26}$ The function of $\mathrm{Lp}(\mathrm{a})$ is unknown but these particles may be involved in clearance of oxidized phosphocholine phospholipids (OxPL) or their Schiff-based adducts to lysine resides in proteins. ${ }^{27}$ OxPL have multiple atherogenic and signaling properties. $^{28} \mathrm{Lp}$ (a) infiltrates into the arterial intima, space and binds to components of the extracellular matrix, enhancing macrophage infiltration and smooth muscle proliferation possibly through the effects of OxPL on macrophage function mediated by $\mathrm{K}-\mathrm{IV}_{10}$ phospholipid-binding domain, interleukin-8, and the lipid scavenger receptor CD-36 and Toll-like-receptor-2 (TLR2). ${ }^{29,30}$ These 


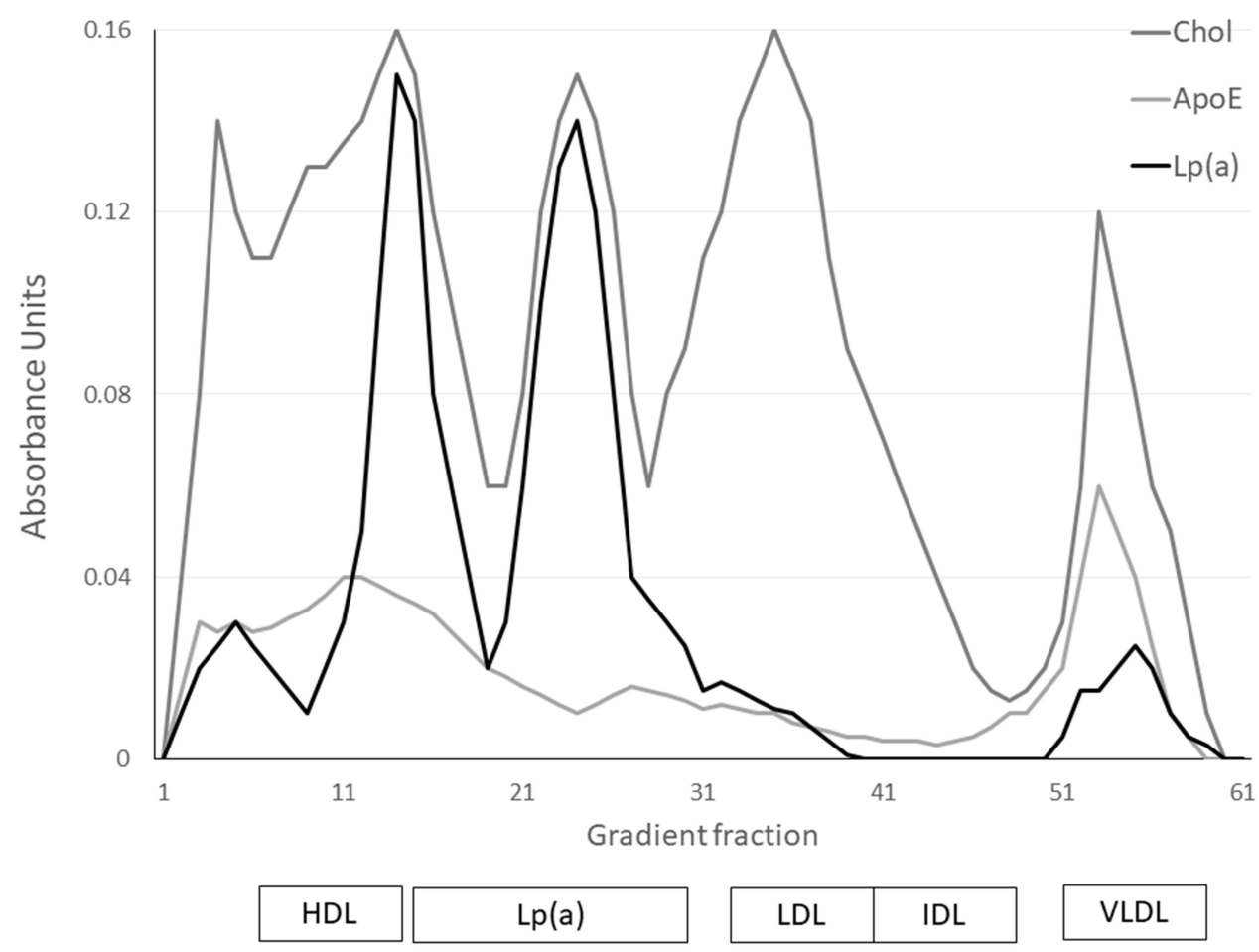

Figure I Distribution of $L_{p}(a)$ within a density gradient profile compared to other lipid fractions showing the association of the distribution of apolipoprotein E with subfractions of $\operatorname{Lp}(\mathrm{a})$.

mechanisms may be relevant to disease, as in the Dallas Heart Study $(n=3381)$, OxPL, apoB, Lp(a) and OxPL/ apoB levels differed between racial/ethnic subgroups, with blacks having the highest levels. OxPL/apoB levels correlated with $\operatorname{Lp}(\mathrm{a})(\mathrm{r}=0.85, \mathrm{p}<0.001)$ with the relationship being a "reverse L" shape for log-transformed values but not other CVD risk factors. The correlation was dependent on apo(a) isoform size; and became weaker with larger isoforms. The number of K-IV repeats negatively correlated with $\mathrm{OxPL} / \mathrm{apoB}(\mathrm{r}=-0.49, \mathrm{p}<0.001)$ and $\mathrm{Lp}(\mathrm{a})$ $(\mathrm{r}=-0.61, \mathrm{p}<0.001)$ but even after adjustment for apo(a) isoform size, the relationship between OxPL/apoB and $\mathrm{L} p$ (a) remained $(\mathrm{r}=0.67, \mathrm{p}<0.001){ }^{31}$

The structural similarity of apo(a) to plasminogen could enhance anti-fibrinolytic effects and have been reported in biochemical studies. ${ }^{25}$ However, an analysis of Dal-Outcomes study failed to demonstrate any effect of $\mathrm{Lp}$ (a) in increasing thrombosis in patients with recent acute coronary syndromes where thrombosis was the main precipitant of events. ${ }^{32}$

Lipoprotein turnover studies of lipoprotein particles using labeled amino acids have been conducted for many years for VLDL and LDL. However, the lower concentration of $\mathrm{Lp}$ (a) limited the application of these techniques until recently. Leucine-label protein turnover studies of
$\mathrm{Lp}$ (a) show that plasma levels are dependent on production rate and isoform $\operatorname{size}^{33}$ and have confirmed the far longer half-life of $\mathrm{Lp}$ (a) compared to LDL. ${ }^{34}$

A lipid turnover study in patients with FH (LDLR or PCSK9 gain-of-function mutations) those with PCSK9 loss-of-function mutations and controls. ${ }^{35}$ Subjects with PCSK9-loss-of-function mutations displayed reduced apoE concentrations associated with a reduced VLDLapoE production rate. $\mathrm{Lp}(\mathrm{a})$ and VLDL-apoE absolute production rates were correlated $(r=0.50 ; P<0.05)$ and apoE:apo(a) ratios in $\mathrm{Lp}(\mathrm{a})$ increased with plasma $\mathrm{Lp}(\mathrm{a})$ $(r=0.96 ; P<0.001)$ but not with PCSK9 levels. Individuals with loss-of-function variants in PCSK9 (ie, increased LDL receptor expression) show lower concentrations of $\mathrm{Lp}$ (a) (63 vs $80 \mathrm{nmol} / \mathrm{L} ; \mathrm{p}<0.001){ }^{36}$

\section{Epidemiology of Lp(a) and Cardiovascular Disease}

Numerous studies have described an association between elevated Lp(a) and CVD independent of LDL-C and other traditional CVD risk factors. ${ }^{11,12,37}$ These associations apply to mortality, CVD mortality, and individual vascular bed endpoints ${ }^{37}$ - myocardial infarction, ${ }^{38}$ stroke and peripheral arterial disease (PAD) in multiple populations 
mostly of European origin. Two studies of the Danish general population included $\mathrm{Lp}(\mathrm{a})$ concentration $(\mathrm{n}=$ 69,764), LPA $\mathrm{K}-\mathrm{IV}_{2}$ repeats $(\mathrm{n}=98,810)$, and $L P A$ rs10455872 genotype $(\mathrm{n}=119,094)$. An $\mathrm{Lp}(\mathrm{a})>93 \mathrm{mg} / \mathrm{dL}$ (199 nmol/L; 96th-100th centiles) compared with $<10 \mathrm{mg} / \mathrm{dL}(18 \mathrm{nmol} / \mathrm{L} ; 1 \mathrm{st}-50 \mathrm{th}$ centiles $)$ was associated with a hazard ratio (HR) of 1.50 (95\% confidence interval 1.28-1.76) for CVD mortality and of 1.20 (1.10-1.30) for all-cause mortality. A $50 \mathrm{mg} / \mathrm{dL}(105 \mathrm{nmol} / \mathrm{L})$ increase in Lp(a) levels had a hazard ratio of 1.16 (1.09-1.23). For stroke, the multivariable-adjusted HR was 1.60 (1.24 to 2.05) and for a $50 \mathrm{mg} / \mathrm{dl}(105 \mathrm{nmol} / \mathrm{l})$ higher $\mathrm{Lp}(\mathrm{a})$ the HR was 1.20 (1.13 to 1.28$){ }^{39}$ In the European Prospective Investigation of Cancer (EPIC)-Norfolk cohort with 212,981 person-years, Lp(a) levels were associated with PAD and CAD outcomes but not with ischemic stroke with HRs per 2.7-fold increase in Lp(a) of 1.37 (1.251.50), $1.13 \quad(1.04-1.22)$ and $0.91 \quad(0.79-1.03)$ respectively. $^{40}$ In the Copenhagen General Population Study (CGPS), patients with familial hypercholesterolemia (FH) with $\mathrm{Lp}$ (a) levels $>50 \mathrm{mg} / \mathrm{dl}$ had a 1.4-fold HR of MI than those with FH and Lp(a) levels $<50 \mathrm{mg} / \mathrm{dl}^{41}$

A study in UK Biobank in 370,049 individuals showed that a $120 \mathrm{nmol} / \mathrm{L}$ increase in $\mathrm{Lp}$ (a) was associated with an
1.26 (1.23-1.28) excess risk of CVD while an intra-genic genetic risk score of $>120$ based on 43 single nucleotide polymorphisms gave similar results with an excess risk of 1.29 (1.26-1.33). ${ }^{15}$ (figure 2) Area under receiver operator curve (AUROC) was $0.64-0.642$ for both methods but would be lower using a precision recall curve (AUPRC) which makes no assumption about balanced numbers in outcome groups.

Meta-analyses of epidemiological studies including the Emerging Risk Factors collaboration (36 studies; $n=126,634)$. In the 24 cohort studies, the risk ratio for CHD (adjusted for age and sex) was 1.16 (1.11-1.22) per 3.5-fold higher Lp(a) concentration (ie, per $1 \mathrm{SD}$ ), and 1.13 (1.09-1.18) following further adjustment for lipids and other risk factors. The adjusted risk ratio for stroke was $1.10(1.02-1.18) .{ }^{37}$ A plasma concentration of $20 \mathrm{mg} /$ dl $(50 \mathrm{nM})$ was associated with a 1.5 -fold risk elevation while levels exceeding $50 \mathrm{mg} / \mathrm{dl}(125 \mathrm{nmol} / \mathrm{L})$ were associated with a 2-fold risk elevation. ${ }^{37}$

As patients with CVD are now routinely treated with statins, there is increasing interest in the role of factors that drive recurrent events. Long-established data from epidemiological studies such as the Framingham Heart Study have identified age, standard lipid fractions, blood

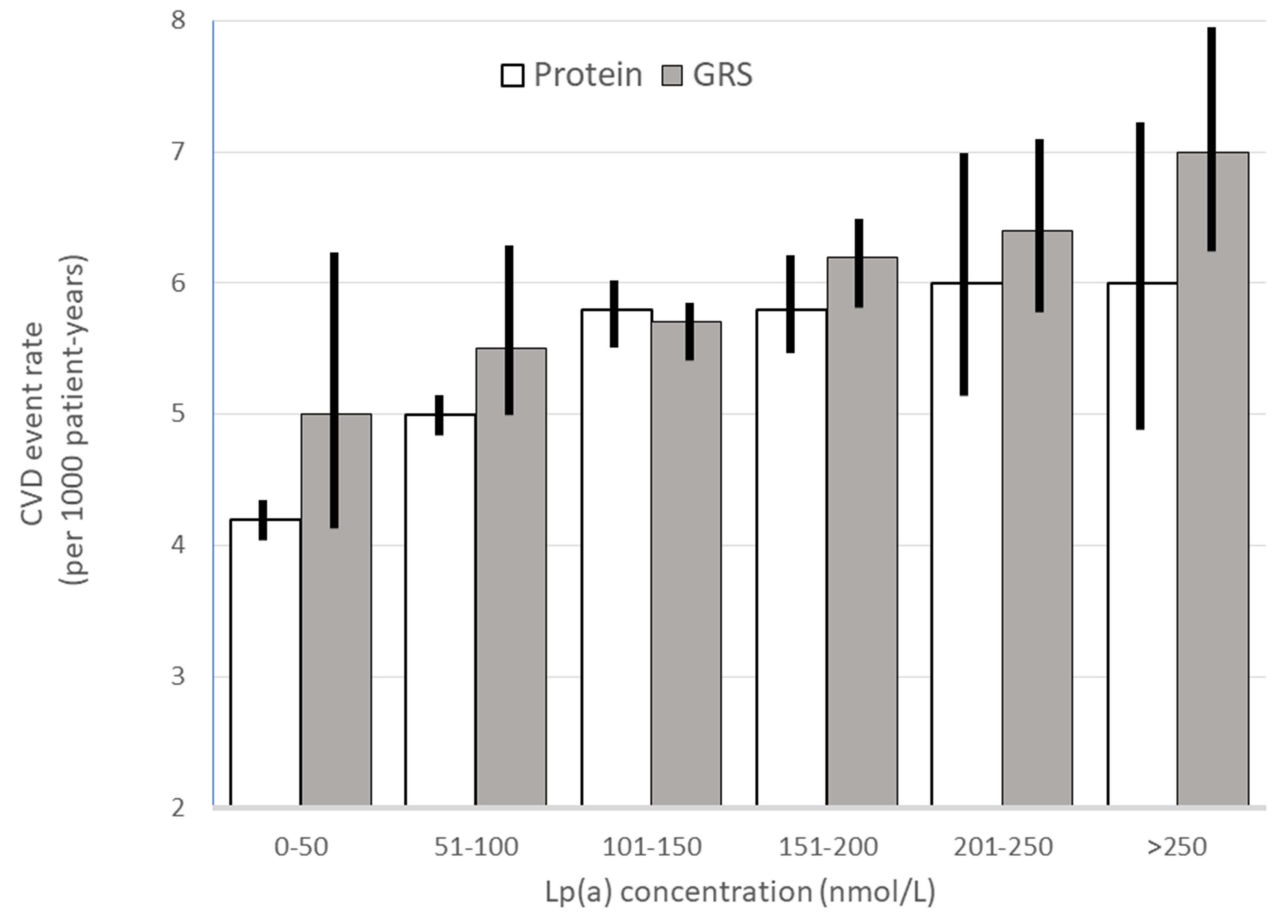

Figure 2 Relationship of measured Lp(a) levels and an equivalent polygenic risk score with CVD events in the UK Biobank study. Data from Trinder et al. ${ }^{15}$ 
pressure, and diabetes as major predictors of recurrent events. $^{42}$ In a study of 3359 patients from the Atherothrombosis Intervention in Metabolic Syndrome with low HDL/HIGH Triglycerides (AIM-HIGH) trial HRs for CVD events adjusted for age, gender, trial treatment, LDL-C, and other risk factors showed HRs increasing from 1.04 (0.82 to 1.32$)$ to 1.51 (1.25 to 1.84$)$ for Lp(a) $15-30 \mathrm{mg} / \mathrm{dl}$ up to $>70 \mathrm{mg} / \mathrm{dl}$ (Figure $3 .^{43}$ A continuous relation for total events was observed $(\mathrm{HR}=1.08$ (1.04 to 1.12$))$ per $20 \mathrm{mg} / \mathrm{dL}$ greater $\mathrm{Lp}(\mathrm{a})$.

Data on the relationship of Lp(a) levels with CVD risk in non-Caucasian populations are scarce and/or underpowered. $^{44}$ The multi-ethnic INTERHEART study of 12,943 subjects reported data from 7 populations showing that Africans $(n=775)$ have the highest Lp(a) concentrations $(27 \mathrm{mg} / \mathrm{dl})$ and smallest isoform size (median $=24 \mathrm{~K}-\mathrm{IV}_{2}$ repeats) while Chinese $(\mathrm{n}=4443)$ ethnicity have the lowest concentrations $(8 \mathrm{mg} / \mathrm{dl})$ and a median of 28 kringle repeats. ${ }^{45}$ Higher Lp(a) concentrations are associated with an increased risk of CVD in all populations but the exact thresholds for different risk levels vary by ethnic group. ${ }^{13,37}$ In West Africans, 3 polymorphisms and rare variants seem to account for the change in distribution. $^{46}$
As most Caucasians have minimal Lp(a) concentrations through inheritance of high copy number K-IV alleles, high Lp(a) levels (low copy K-IV number) tend to show an autosomal dominant pattern of inheritance. Given the association of higher Lp(a) with CVD this suggests that $\mathrm{Lp}$ (a) should co-segregate with a family history of premature CVD. The Atherosclerosis Risk In Communities (ARIC) study included 12,149 subjects of average age 54 years, $56 \%$ women, $23 \%$ black, and $44 \%$ with a family history of CVD. Of these, 3114 had CVD events over 21 years of follow-up. Both family history (HR 1.17 (1.09-1.26)) and elevated Lp(a) (HR 1.25 (1.12 to 1.40$)$ ) were independently associated with CVD with no interaction $(p=0.75){ }^{47}$ The highest risk was seen in those with a family history and high Lp(a) (HR: 1.43 (1.27 to 1.62)). Similar findings in ARIC were observed for coronary heart disease (CHD) risk in this study and in another for risk of stroke, ${ }^{48}$ and in analyses stratified by family history of premature CHD, as well as in the Dallas Heart Study cohort which had a higher proportion of AfricanAmericans. ${ }^{47}$ In parallel with observational data from epidemiological studies, Mendelian randomization analyses provide strong evidence that the association between Lp(a) and risk of CVD is likely to be causal. ${ }^{12,13,38,49}$

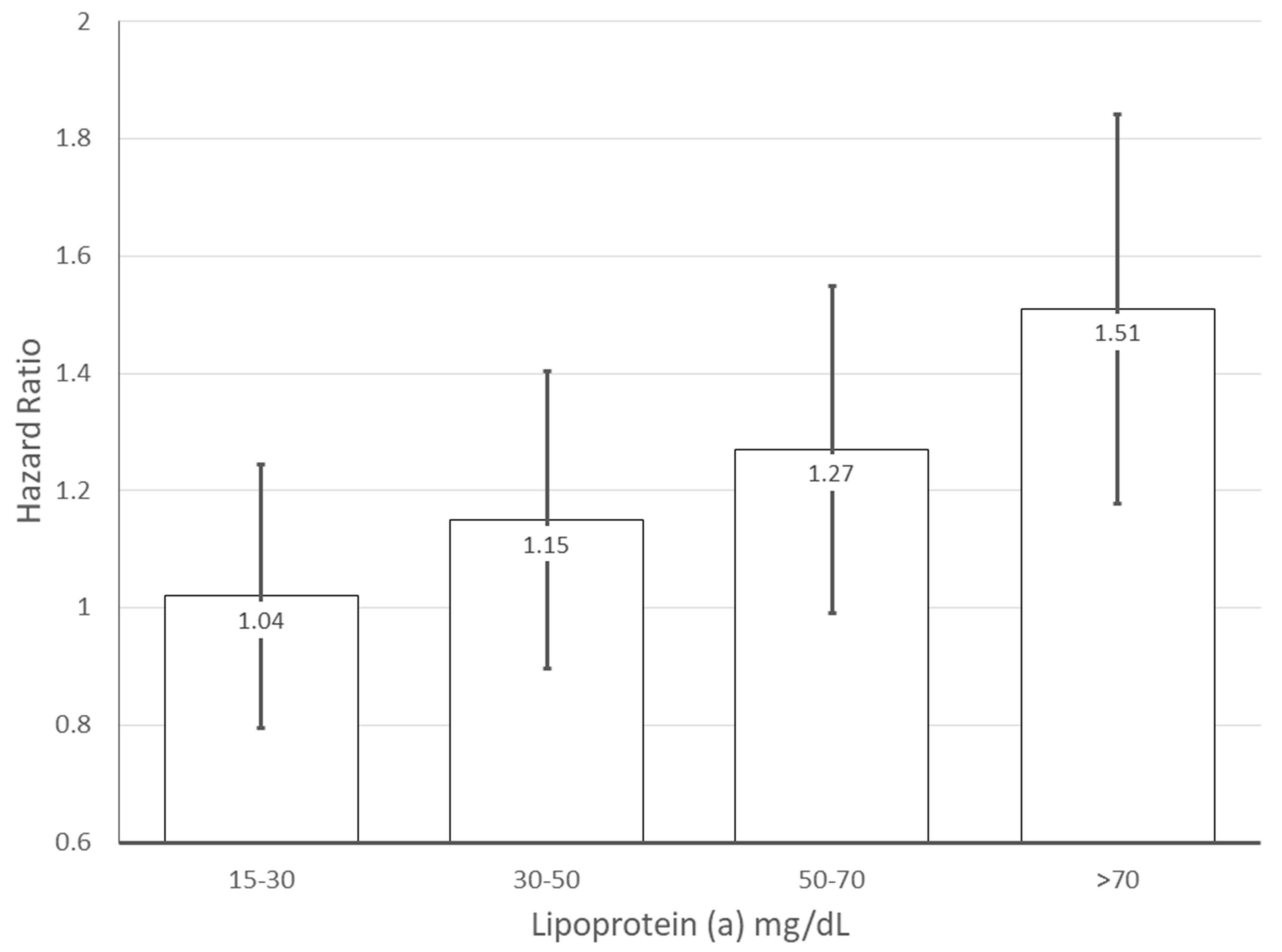

Figure 3 Relationship of increasing levels of Lp(a) within the AIM-HIGH study with CVD events. Lp(a) 0-I5nM is taken as the reference group. Reproduced from Wong ND, Zhao Y, Sung J, Browne A. Relation of first and totalrecurrent atherosclerotic cardiovascular disease events toincreased lipoprotein(a) levels among statin treated adults withcardiovascular disease. Am J Cardiol. 2021;145:12-17. () 202। Elsevier Inc. All rights reserved. ${ }^{43}$ 
A post hoc analysis of intravascular ultrasound regression trials (6 trials; 3943 patients) stratified into high ( $\geq 60 \mathrm{mg} / \mathrm{dL} ; 17 \%)$ (17\%) and low $(<60 \mathrm{mg} / \mathrm{dL} ; 83 \%)$ baseline serum $\mathrm{Lp}$ (a) showed that percent atheroma volume (PAV) was higher in the high $\mathrm{Lp}$ (a) group before adjustment for CVD risk factors (38 (33-44)\% vs 37 (3143), $\mathrm{P}=0.01)$ and more clearly after adjustment $(39 \% \pm 0.5$ vs $38 \% \pm 0.5, \quad \mathrm{P}<0.001)$. Risk-adjusted PAV increased across quintiles of $\mathrm{Lp}$ (a) $(1-5 ; 37 \pm 0.5 \%, 37 \pm 0.5 \%, 37$ $\pm 0.5 \%, 38 \pm 0.5 \%, 39 \pm 0.5 \%, \mathrm{P}=0.002){ }^{50}$

Relationships of $\mathrm{Lp}(\mathrm{a})^{51,52}$ with $\mathrm{OxPL}^{53,54}$ have also been shown in aortic stenosis and this association may explain part of the atheromatous appearance of degenerative aortic valve disease. ${ }^{55}$ Whether the association also occurs in mitral valve disease as opposed to mitral annulus calcification is unclear. ${ }^{56}$

\section{Lp (a) Measurement}

The standardized accurate measurement of Lp(a) concentrations remains a challenge. The mass measurement of $\mathrm{Lp}$ (a) includes all of the cholesterol, cholesterol esters, phospholipids, apoB $\mathrm{B}_{100}$ and apo(a). The variability in $\mathrm{K}$ $\mathrm{IV}_{2}$ repeats will thus influence the mass concentration whilst also rendering multiple epitopes available for immunoassays thereby making standardization with a single calibrant impossible. ${ }^{57,58}$ Furthermore, immunoassays must be specific for antigenic loci of apo (a) that are not present in plasminogen or apoB and are specific for $\mathrm{K}$ $\mathrm{IV}_{2}$ which is a major contributor to apo(a) polymorphism. An example is an enzyme linked immunosorbent assay (ELISA) method employing monoclonal antibodies that are specific for a unique apo(a) epitope located in $\mathrm{K}-\mathrm{IV}_{9}$ which shows excellent agreement with an ultraperformance liquid chromatography/mass spectrometry method. ${ }^{57}$ The selection of assay calibrators is difficult given the high degree of apo(a) size/ $\mathrm{KIV}_{2}$ copy number variation but most kits now use 5-point calibration. Results should be expressed in nmol/l of Lp(a) particles, yet most of the previous literature reports $L p(a)$ concentrations in mass units and most papers do not specify the platform or traceability of reference materials. The use of a conversion factor of 2.4 to convert mass to molar units is not recommended given errors involved. ${ }^{57}$

A further complication is that most $\mathrm{Lp}$ (a) forms part of the small dense sub-fraction within the spectrum of LDL particle subspecies. It exists as 3 subspecies running in the VLDL fraction as a triglyceride-rich apoB-apo(a) particle, a subfraction of apoB-apo(a) with added apoE and an LDL
apoB-apo(a) fraction. The density of $\mathrm{Lp}(\mathrm{a})$ means that it forms part of the calculated LDL-C (cLDL-C) level reported using the Friedewald equation by most laboratories. A number of formulae have been proposed to correct cLDL-C for $\mathrm{Lp}(\mathrm{a})-\mathrm{C}$ but none have been widely adopted. ${ }^{59}$ Furthermore, the precipitation of $\mathrm{Lp}(\mathrm{a})$ by most direct LDL-C methods may vary.

Assays measuring $\mathrm{Lp}(\mathrm{a})$-cholesterol content have been devised using lectin-based, ${ }^{60}$ ultracentifugation ${ }^{61,62}$ or immunofixation electrophoresis ${ }^{63}$ methods. The lectin $\mathrm{Lp}(\mathrm{a})-\mathrm{C}$ assay was assessed in the Framingham Heart study ( $\mathrm{n}=3121) .{ }^{60}$ The mean $\mathrm{Lp}(\mathrm{a})-\mathrm{C}$ concentration in men with CHD $(\mathrm{n}=156)$ was $0.24 \pm 0.20 \mathrm{mmol} / \mathrm{L}$ and $34 \%$ higher than in controls $(\mathrm{P}<0.001)$. The odds ratio for CHD risk in men with $\mathrm{Lp}(\mathrm{a})-\mathrm{C}>0$. $259 \mathrm{mmol} / \mathrm{L}$ $(>10 \mathrm{mg} / \mathrm{dL})$ was $2.29(1.55-3.94 ; \mathrm{p}<0.001)$. In this case, Lp(a)-C correlated highly with a mass immunoassay (Apotek $^{\mathrm{TM}} \mathrm{Lp}(\mathrm{a})$; $\mathrm{r}=0.83$; $\mathrm{P}<0.0001$ ). This finding was not reproduced in the Framingham Offspring study. ${ }^{64}$ For other methods $\mathrm{Lp}(\mathrm{a})-\mathrm{C}$ shows a modest correlation with ELISA mass methods ( $\mathrm{r}=0.56$; $\mathrm{P}$ 0.01-0.001) accounting for $31 \%$ of the variance ${ }^{61}$ but results are often discordant. ${ }^{62} \mathrm{~A}$ new assay based on magnetic particlebased isolation of Lp(a) may be more practical. ${ }^{65}$ High Lp(a)-C levels may have an effect on calculated LDL-C and may affect classification in $38 \%$ of patients if an adjustment formula is used ${ }^{59}$ and even $3 \%$ of individuals for FH risk categories using the Dutch Lipid score. ${ }^{66}$ They might also affect the eligibility for therapies which are dependent on LDL-C levels such as proprotein convertase subtilisin kexin-9 (PCSK-9) inhibitors.

\section{Lp (a) and Current Guidelines}

Consensus groups and expert opinion suggest that $\mathrm{Lp}(\mathrm{a})$ should be measured at least once in high risk groups such as those with established CVD or with a family history of early onset CVD. ${ }^{24,67}$

In 2010, the European Atherosclerosis Society (EAS) Consensus Panel recommended screening for Lp (a) in a number of risk groups ${ }^{11}$ (Table 1). These categories were slightly amended in the 2019 European Society of Cardiology (ESC) guidelines for the management of dyslipidemia. ${ }^{68}$ Similar statements on measuring $L p(a)$ in patients at higher risk of CVD have been made by the US American Heart Association ${ }^{70}$ and in detail by the National Lipid Association. ${ }^{69}$ All these guidelines recommend that $\mathrm{Lp}(\mathrm{a})$ is measured once and used as an additional risk stratification tool especially in high-risk groups for CVD. 
Table I Summary of Groups Recommended for Lipoprotein (a) Testing in Different International Guidelines

\begin{tabular}{|c|c|c|c|c|}
\hline Category & EAS (2010)" & $\operatorname{ESC}(2019)^{68}$ & NLA $^{69}$ & NICE \\
\hline Premature CVD & Undefined & $\begin{array}{l}<55 \text { yrs male } \\
<60 y \text { rs female }\end{array}$ & $\begin{array}{l}<55 \text { yrs male } \\
<60 y \text { rs female } \\
\text { Stroke }<55 \text { yrs }\end{array}$ & No \\
\hline $\begin{array}{l}\text { Familial } \\
\text { Hypercholesterolemia }\end{array}$ & Yes & Yes & Yes & No \\
\hline $\begin{array}{l}\text { Family history of premature } \\
\text { CVD }\end{array}$ & Yes & Yes & Yes & No \\
\hline $\begin{array}{l}\text { Family history of elevated } \\
\text { Lp(a) }\end{array}$ & Yes & Yes & No & No \\
\hline $\begin{array}{l}\text { Recurrent CVD despite statin } \\
\text { treatment }\end{array}$ & Yes & Yes & $\begin{array}{l}\text { Yes plus inadequate } \\
\text { LDL-C response }\end{array}$ & No \\
\hline Primary prevention & $\begin{array}{l}>3 \% \text { 10-year risk of fatal CVD (Systemic } \\
\text { Coronary Risk Evaluation (SCORE) } \\
\text { calculator) }\end{array}$ & $\begin{array}{l}\geq 5 \% \text { 10-year risk of fatal CVD } \\
\text { Systemic Coronary Risk Evaluation } \\
\text { (SCORE) }\end{array}$ & $\begin{array}{l}>10 \% 10 \text {-year risk of } \\
\text { fatal and/or non-fatal } \\
\text { CHD }\end{array}$ & No \\
\hline $\begin{array}{l}\text { Risk of progressing aortic } \\
\text { stenosis }\end{array}$ & No & No & Yes & No \\
\hline $\begin{array}{l}\text { Reclassification around } \\
\text { primary prevention risk } \\
\text { threshold }\end{array}$ & No & Yes & Yes $(7.5-19.9 \%$ risk) & No \\
\hline $\begin{array}{l}\text { Reclassification around } \\
\text { secondary prevention } \\
\text { monitoring interval }\end{array}$ & No & No & Yes & No \\
\hline
\end{tabular}

In the UK, NICE guidelines have not reviewed the role of Lp(a) and neither has the National Screening committee reviewed whether it should be measured as part of CVD risk assessment. The HEART-UK consensus statement ${ }^{71}$ reproduced guidance from the ESC in the absence of assessment from NICE. These guidelines suggest a desirable level $\mathrm{Lp}$ (a) $<50 \mathrm{mg} / \mathrm{dl}$ for patients with established CVD if the primary goal of LDL-C lowering had been achieved, partly based on this level being the 80th centile of the general population distribution. ${ }^{11}$ Other authors have suggested an even lower target of $30 \mathrm{mg} / \mathrm{dl}$ (90th centile). ${ }^{72,73}$

With consensus guidelines recommending $\mathrm{Lp}$ (a) measurement in several patient groups the question on how a result will influence the clinician's clinical decision making needs to be addressed. The use of $\mathrm{Lp}$ (a) levels to reclassify intermediate risk groups in primary prevention is feasible if risk modifiers can be agreed and added to calculator/web systems. Similarly, using Lp(a) as part of reclassification for recurrent disease and amending review intervals may be possible.

\section{Lipid Lowering Therapies Indirectly Affecting $\operatorname{Lp}(a)$}

The effects of interventions on $\mathrm{Lp}(\mathrm{a})$ are very different to those on LDL particles which they partially resemble in structure apart from the addition of apo(a). Diet and lifestyle factors do not seem to influence $\mathrm{Lp}$ (a) concentrations ${ }^{74}$ though this has not been formally well tested in prospective intervention studies. $^{72}$

Most studies that have investigated the effects of medications on $\mathrm{Lp}(\mathrm{a})$ have done this as a secondary endpoint or as a post hoc analysis. These studies (Table 2) generally do not select patients based on $\mathrm{Lp}$ (a) concentration, they are recruited from mostly Caucasian populations and report results either in the whole population or split at median values. Given the highly skewed distribution of $\mathrm{Lp}(\mathrm{a})$ this can lead to contrasting results depending on the population selected. The data on the effects of lipidlowering drug therapies are presented based on metaanalyses of efficacy on Lp(a) levels in clinical trials; lipoprotein turnover studies suggesting the mechanism of 
Table 2 Effects of Different Lipid-Lowering Drugs on Lp(a) Levels, Production and Catabolic Rates in Turnover Studies and Effects on CVD Outcomes Either Combined with LDL-C Changes or if Analyzed for Heterogeneity by Lp(a) Level Within Trials. Lp(a) Specific Studies are Quoted Separately

\begin{tabular}{|c|c|c|c|c|c|}
\hline Intervention & $\begin{array}{l}\text { Baseline } \\
\text { Lp(a) }\end{array}$ & Change in Lp(a) & $\begin{array}{l}\text { Change in } \\
\text { Production Rate (\%) }\end{array}$ & $\begin{array}{l}\text { Change in Fractional } \\
\text { Catabolic Rate (\%) }\end{array}$ & $\begin{array}{l}\text { Change in CVD } \\
\text { Events }\end{array}$ \\
\hline Apheresis & $\begin{array}{l}\text { Usually } \\
>100 \mathrm{nM}\end{array}$ & NA & NA & NA & $\begin{array}{l}54-90 \% \text { (include } \\
\text { LDL-C effect) }\end{array}$ \\
\hline Apheresis Lp(a) study ${ }^{76}$ & $108 \mathrm{nM}$ & $68 \%$ & NA & NA & $\begin{array}{l}81 \% \text { (includes LDL- } \\
\mathrm{C} \text { effect) }\end{array}$ \\
\hline Statins & Variable & $\begin{array}{l}\text { Nil but } \\
\text { distribution shift }\end{array}$ & NA & NA & No differential \\
\hline Fibrates & Variable & $-2.7 \mathrm{mg} / \mathrm{dL}$ & NA & NA & No differential \\
\hline Niacin & Variable & $-23 \%$ & -50 & -37 & No differential \\
\hline $\begin{array}{l}\text { Niacin Lp(a) analysis } \\
(\text { THRIVE) }\end{array}$ & $128 \mathrm{nM}$ & $-31 \%(\mid 2-34 n M)$ & NA & NA & No differential \\
\hline PCSK9 inhibitor & $\begin{array}{l}\text { Mean } 21 \\
\text { or } 25 \mathrm{nM}\end{array}$ & -25 to $27 \%$ & $\begin{array}{l}\text { Reduced } \\
\text { (monotherapy only) }\end{array}$ & $\begin{array}{l}\text { Reduced (combination with } \\
\text { statin only) }\end{array}$ & $\begin{array}{l}\text { No clear } \\
\text { differential }\end{array}$ \\
\hline $\begin{array}{l}\text { Mipomersen (apoB antisense } \\
\text { oligonucleotide) }\end{array}$ & Not stated & $-26 \%$ & Nil & -27 & NA \\
\hline CETP inhibitor & Variable & $\begin{array}{l}-5 \% \text { dalcetrapib } \\
\text { (low efficacy) } \\
-30 \text { to } 40 \% \text { (high } \\
\text { efficacy) }\end{array}$ & $-41 \%$ & $\mathrm{Nil}$ & No differential \\
\hline
\end{tabular}

Abbreviations: CETP, cholesterol ester transfer protein; MTP, microsomal transfer protein; PCSK9, proprotein convertase subtilisin kexin 9.

any effect (production or catabolism) and any CVD outcome trial event data stratifying by $\mathrm{Lp}(\mathrm{a})$ concentration.

\section{Lipoprotein Apheresis}

Apheresis methods including apheresis reduce $\mathrm{Lp}(\mathrm{a})$ levels about $65-75 \%$ immediately post-procedure and $40-50 \%$ on standard schedules. Most descriptions of the effects have involved apheresis techniques that remove LDL and Lp(a) particles with the majority of cases having concurrent homozygous or heterozygous FH but a smaller fraction with severe vascular disease, polygenic hypercholesterolemia, and high Lp(a) levels. A systematic review of early studies showed that apheresis reduced CVD events by $54-90 \%{ }^{75}$ A later study of 154 patients with baseline Lp(a) 108mg/dL showed apheresis reduced $\mathrm{Lp}$ (a) by $68 \%$ and reduced CVD events by $81 \%{ }^{76}$ One variant of apheresis (Lipopac) is specific for removing $L p(a)$ but data on this intervention are limited. In a study of 15 patients, Lp(a) specific apheresis reduced Lp(a) by $75 \%$ and showed angiographic benefit. ${ }^{77}$

\section{Statins and $L p(a)$}

Most meta-analyses of the effects of statins ( $\mathrm{n}=20 ; 23,605$ patients) show minimal effect of these drugs on $\mathrm{Lp}(\mathrm{a})$ levels ${ }^{78}$ but selecting on uniform assays (6 studies; 5526 patients) gave different results. ${ }^{79}$ The only major study showing a different effect was JUPITER (Justification for the Use of Statins in Prevention: an Intervention Trial Evaluating Rosuvastatin). Rosuvastatin therapy raised Lp(a) by $10 \%$ in a study of 9612 multi-ethnic patients (7746 Caucasian). Lp(a) concentrations (median (25-75th centile); nmol/L) were highest in blacks (60 (34-100)), then Asians (38 (18-60)), Hispanics (24 (11-46)), and whites $(23(10-50)){ }^{80}$ The median change in $\mathrm{Lp}(\mathrm{a})$ with rosuvastatin was zero, but statin therapy resulted in a positive shift in the $\mathrm{Lp}(\mathrm{a})$ distribution $(\mathrm{P}<0.0001)$. Rosuvastatin reduced CVD by 38\% (HR 0.62 (0.430.90)) with $\mathrm{Lp}(\mathrm{a})$ above the median and $54 \%$ in those with Lp(a) below the median (HR $0.46(0.30-0.72)$ ), with no evidence of interaction. ${ }^{80}$ The effect of statins on 
$\mathrm{Lp}(\mathrm{a})$ is likely neutral but may be confounded by insulin resistance, or isotype distribution.

\section{Other Established Lipid-Lowering Drugs}

A meta-analysis (16 studies; 1388 patients) showed fibrates have a small effect in reducing $\mathrm{Lp}$ (a) (2.7 (0.84.5) $\mathrm{mg} / \mathrm{dl}$ ) which is increased in combination therapy with statins. ${ }^{81}$ Drugs with a primary site of action in the gut such as ezetimibe (an enterocyte-acting Niemann PickC1-like protein 1 (NPC1L1) antagonist) ${ }^{82}$ have no effect on Lp(a) and the bile acid sequestrant cholestyramine showed similar effects in the Lipid Research Clinics study. ${ }^{83}$ There are little data on the effects of bempedoic acid (a hepatic acid-citrate lyase inhibitor) on $\mathrm{Lp}(\mathrm{a}) .^{84}$

\section{Niacin and Lp(a)}

A meta-analysis of studies (14 studies; $n=14,375)$ with niacin have shown that this treatment reduces $\mathrm{Lp}(\mathrm{a})$ by 23 (19-27\%). ${ }^{85}$ A crossover design lipoprotein turnover study in 8 patients treated with extended-release niacin showed it decreased triglycerides by $46 \%$, raised HDL-C by $20 \%$, and decreased apo(a) concentrations by $20 \%$. It decreased apoB $_{100}$ by $22 \%$ and PCSK 9 levels by $-29 \%$. Apo(a) production rates were decreased by $50 \%$ and fractional catabolic rate by $37 \%{ }^{86} \mathrm{~A}$ further study of niacin treatment showed reductions in $\mathrm{Lp}(\mathrm{a})$ and VLDL-apoE absolute production rate were correlated $(r=0.83$; $P=0.015)$. In contrast, PCSK9 reduction $\quad(-35 \%$; $P=0.008$ ) was only correlated with that of VLDL-apoE absolute production rate $(r=0.79 ; P=0.028){ }^{35}$

Coronary and carotid artery regression studies show the predicted effect of baseline $\mathrm{Lp}(\mathrm{a})$ on risk of progression but no effect of niacin therapy in post hoc mediansplit analyses where diabetes, metabolic syndrome and nonHDL-cholesterol predicted effects. ${ }^{87}$ In outcome studies, Lp(a) was not measured in the Coronary Drug Project but it was measured in the AIM-HIGH ${ }^{88}$ and HPS/ THRIVE studies. ${ }^{89}$ The increased risk of events with baseline Lp(a) was seen in both studies. Niacin has multiple beneficial effects on lipid profiles including on $\mathrm{Lp}(\mathrm{a})$ but neither study showed any reduction in CVD events. A prespecified analysis of HPS2/THRIVE investigated the effect of niacin-laropiprant on $\mathrm{Lp}(\mathrm{a})$ and CVD risk. ${ }^{90}$ Niacin therapy reduced mean $\mathrm{Lp}(\mathrm{a})$ by 12 (SE, 1) nmol/ $\mathrm{L}$ overall and $34(6) \mathrm{nmol} / \mathrm{L}$ in the top quintile of $\mathrm{Lp}(\mathrm{a})$ $(>128 \mathrm{nmol} / \mathrm{L})$. The mean reduction in $\mathrm{Lp}(\mathrm{a})$ with niacin was $31 \%$ but varied with predominant apolipoprotein(a) isoform size $\left(\mathrm{P}_{\text {Trend }}=4 \times 10^{-29}\right)$ but was only $18 \%$ in the highest quintile ( $\mathrm{Lp}(\mathrm{a})>128 \mathrm{nM})$ with low isoform size. ${ }^{90}$

\section{PCSK9 Inhibitors and Lp(a)}

PCSK9 inhibitors, like statins, modulate expression of the LDL receptor. However, the 2 drug classes have different effects on Lp(a). Meta-analysis of the effects of PCSK9 inhibitors (41 studies; $n=64,107$ ) showed reduced Lp(a) by $28 \%$ in contrast to the lack of effect of statins. ${ }^{91}$ Lipoprotein turnover studies with PCSK9 inhibitors have shown confusing effects with a reduction in particle synthesis with monotherapy but changing to increased catabolism in combination with statins. ${ }^{92}$

Subgroup analyses of the FOURIER and ODYSSEYOutcomes trials showed that higher baseline Lp(a) predicted CVD risk and thus was associated with a greater absolute risk of CVD reduction. In the FOURIER trial, in 27,564 patients with CVD, evolocumab reduced Lp(a) by a median 27 (6-47)\%. ${ }^{93}$ The change in Lp(a) of median 25 $(6-47) \mathrm{nmol} / \mathrm{L}$ correlated with change in LDL-C $(\mathrm{r}=0.37$; $\mathrm{p}<0.001$ ). Evolocumab reduced CVD events by $23 \%$ (HR $0.77(0.67-0.88))$ in patients with above median $\mathrm{Lp}(\mathrm{a})$ and by $7 \%$ (HR $\left.0.93(0.80-1.08) ; \mathrm{P}_{\text {interaction }}=0.07\right)$ in those below the median level. The higher baseline risk of $2.49 \%$ vs $0.95 \%$ and the greater absolute risk reductions translate to a number needed to treat over 3 years $\left(\mathrm{NNT}_{3}\right)$ of 40 vs 105 individuals. $^{93}$ The $25 \mathrm{nmol} / \mathrm{L}(12 \mathrm{mg} / \mathrm{dL})$ reduction in $\mathrm{Lp}$ (a) corresponded to a $15 \%$ reduction in CVD events. ${ }^{94}$

Data from 4 Phase 3 trials with evolucumab comprising 895 patients showed heterogeneity between LDL-C and Lp(a) effects. ${ }^{95}$ Concordance was defined as LDL-C reduction $>35 \%$ and $\mathrm{Lp}$ (a) reduction $>10 \%$. A discordant response was observed in $20 \%$ of patients with a higher prevalence in those with baseline $\mathrm{Lp}(\mathrm{a})$ concentrations $>30 \mathrm{mg} / \mathrm{dL}(26.5 \%)$ or $>50 \mathrm{mg} / \mathrm{dL}(28.6 \%) .{ }^{95}$

The ODYSSEY-Outcomes study randomized 18,924 patients to alirocumab or placebo and followed them for 2.8 years. Baseline Lp(a) levels were $21(7-60) \mathrm{mg} / \mathrm{dl}$ and predicted CVD events. ${ }^{96}$ Alirocumab reduced Lp(a) by 5.0 $(0-14) \mathrm{mg} / \mathrm{dl}$, LDL-C by $51(34-67) \mathrm{mg} / \mathrm{dl}$, and reduced CVD events by $15 \%$ (HR 0.85 (0.78-0.93)). Alirocumabinduced reductions of $\mathrm{Lp}(\mathrm{a})$ and LDL-C independently predicted lower risk of CVD events, after adjustment for baseline concentrations, demographics and clinical characteristics. In a further analysis, ODYSSEY-Outcomes higher baseline $\mathrm{Lp}(\mathrm{a})$ levels were associated with 
a greater reduction in CVD events with alirocumab (HR $\left.\mathrm{P}_{\text {trend }}=0.045\right) .{ }^{97} \mathrm{~A} 1 \mathrm{mg} / \mathrm{dl}$ reduction in $\mathrm{Lp}(\mathrm{a})$ with alirocumab was associated with a $0.6 \%$ reduction in CVD events $^{96}$ while a $5 \mathrm{mg} / \mathrm{dL}$ reduction in $\mathrm{Lp}$ (a) predicted a $2.5 \%$ reduction in CVD events. ${ }^{97}$

A post hoc analysis of the ODYSSEY program (10 trials) also showed discordance between $\operatorname{Lp}(\mathrm{a})$ and LDL-C responses. The total prevalence of discordant LDL-C/Lp(a) responses was $13 \%$ with $\mathrm{LDL}-\mathrm{C}>35 \%$ reduction and $\mathrm{Lp}(\mathrm{a})<10 \%$ reduction; and $9 \%$ with $\mathrm{LDL}-$ $\mathrm{C}<35 \%$ reduction and $\mathrm{Lp}(\mathrm{a})>10 \%$ reduction. $^{98}$

Little data are available, as yet, on Inclisiran -a modified siRNA targeting apo(a). In the ORION-1 study with 501 participants a single dose of inclisiran reduced apo B, nonHDL-C, and VLDL-cholesterol over 210 days. A second dose of inclisiran delivered additional lipid lowering. Inclisiran with reduced LDL-C and apoB similar to PCSK9 antibody therapies and $\mathrm{Lp}(\mathrm{a})$ reductions of $15-25 \%$ were obtained. ${ }^{99}$

\section{Antisense Therapy to apoB}

Mipomersen, a second-generation antisense oligonucleotide against apo- $\mathrm{B}_{100}$ was approved to treat homozygous $\mathrm{FH}$ (HoFH) but has now been withdrawn for commercial reasons. It has shown consistent effects in reducing $\mathrm{Lp}(\mathrm{a}){ }^{100}$ Meta-analysis of all four phase 3 randomized trials including 382 patients found that mipomersen reduced Lp(a) by $26 \%{ }^{101}$ A lipoprotein turnover study in 14 healthy individuals using $150 \mathrm{mg}$ mipomersen showed a $21 \%$ reduction in $\mathrm{Lp}$ (a) driven by a $27 \%$ increase in the fractional catabolic rate, but no change in the production rate. ${ }^{102}$

\section{Cholesterol Ester Transfer Protein Inhibitors}

Cholesterol ester transfer protein (CETP) inhibitors reduce Lp(a) levels. Analysis of the Investigation of Lipid Level
Management to Understand its Impact in Atherosclerotic Events (ILLUMINATE) trial showed that Lp(a) was dosedependently increased with increasing atorvastatin doses during optimization. Torcetrapib therapy decreased $\mathrm{Lp}(\mathrm{a})$ by $11 \%{ }^{103}$ Evacetrapib decreased Lp(a) by up to $-40 \%$ with evacetrapib $500 \mathrm{mg}$ in dose ranging studies while evacetrapib combined with statins reduced Lp(a) by $31 \% .{ }^{104}$ Dalcetrapib had lesser effects on lipids than torcetrapib, evacetrapib or anacetrapib and decreased $\mathrm{Lp}(\mathrm{a})$ by $5 \%{ }^{32}$

A lipoprotein turnover study investigated the effects of anacetrapib, statin or combined therapy. Anacetrapib treatment reduced $\mathrm{Lp}(\mathrm{a})$ by $34 \%(\mathrm{P}<0.001)$. The decreases in $\mathrm{Lp}$ (a) levels were caused by a $41 \%$ reduction in the apo(a) production rate, with no effects on fractional catabolic rate. ${ }^{105}$

\section{Specific Therapies for apo(a)}

All the lipoprotein turnover data suggest that intervention on production rate of apo(a) is likely to reduce Lp(a). Antisense technology has been applied to apo(a) as a method of delivering a specific effect. The effect of ISIS 144367, a 2nd generation ASO to apo(a) was initially investigated in transgenic mouse models overexpressing human apo(a). It produced a decrease of 20,30 , and $86 \%$ in the three different models, respectively. ${ }^{106}$ ISIS 144367 was optimized and the new ASO called ISIS-APO(a)Rx was tested in cynomolgus monkeys achieving a reduction of $97 \%$ in hepatic apolipoprotein(a) mRNA of $90 \%$ in $\mathrm{Lp}(\mathrm{a})$ at the highest dose. ${ }^{107}$

The Phase 1 study of ISIS-APO(a)Rx in man $(n=47)$ assigned 16 patients to single-dose treatment and 31 were assigned to a multi-dose cohort treated for 4 weeks (Table 3). After 36 days all 3 treated groups showed 100mg ISIS-APO (a)Rx reduced Lp(a) by 40\%, 200mg 59\%, and 300mg decreased Lp(a) by 79\%. No serious adverse events were seen but one patient stopped due to injection site reaction and another stopped due to flu-like symptoms. ${ }^{108}$

Table 3 Efficacy of Antisense ${ }^{108}$ and GaINAc Conjugated in Single and Multidose ${ }^{110}$ Preclinical Studies

\begin{tabular}{|l|l|l|l|l|l|}
\hline $\begin{array}{l}\text { ISIS-APO(a) } \\
\text { Dose }\end{array}$ & $\begin{array}{l}\text { Trial I Lp(a) } \\
\text { Reduction (\%) }\end{array}$ & $\begin{array}{l}\text { Trial 2 Lp(a) } \\
\text { Reduction (\%) }\end{array}$ & $\begin{array}{l}\text { ISIS-APO(a)Rx } \\
\text { Dose }\end{array}$ & $\begin{array}{l}\text { Trial I Lp(a) } \\
\text { Reduction (\%) }\end{array}$ & $\begin{array}{l}\text { Trial 2 Lp(a) } \\
\text { Reduction (\%) }\end{array}$ \\
\hline 0 & $0(n=4)$ & $0(n=6)$ & 0 & $0(n=3)$ & $0(n=6)$ \\
\hline 50 & $12(n=3)$ & & 10 & $33(n=3)$ & $59(n=8)$ \\
\hline 100 & $19(n=3)$ & $40(n=8)$ & 20 & $33(n=3)$ & $72(n=8)$ \\
\hline 200 & $15(n=3)$ & $59(n=9)$ & 40 & $44(n=3)$ & $72(n=8)$ \\
\hline 300 & $72(n=9)$ & 80 & $79(n=6)$ & $85(n=6)$ & \\
\hline 400 & $36(n=3)$ & & 120 & & \\
\hline
\end{tabular}


The Phase 2 study of ISIS-APO(a)Rx included 64 individuals with 51 assigned to cohort $\mathrm{A}$ with baseline $\mathrm{Lp}$ (a) levels from $50-175 \mathrm{mg} / \mathrm{dL}(125-437 \mathrm{nmol} / \mathrm{L})$ and 13 individuals (cohort B) had baseline Lp(a) levels $>175 \mathrm{mg} / \mathrm{dL}(\geq 438 \mathrm{nmol} / \mathrm{L}) .{ }^{109}$ Both cohorts received $100 \mathrm{mg}$ weekly for 4 weeks, then $200 \mathrm{mg}$ for 4 weeks, and last $300 \mathrm{mg}$ for 4 weeks. ${ }^{109}$ Levels of Lp(a) decreased by $67 \%$ for individuals in cohort $\mathrm{A}$ and $72 \%$ in cohort $\mathrm{B}$, measured on day 85 or 99 . No severe adverse events were recorded; but 2 individuals suffered a myocardial infarction, one in the placebo arm and one after a single dose of ISIS-APO(a)Rx. Regarding mild adverse events, $10 \%$ in cohort A and 19\% in cohort B had injection site reactions.

Further modification of ISIS-APO(a)Rx (renamed IONIS/AKCEA-APO(a)-LRx; pelacarsen) involved adding a triantennary $\mathrm{N}$-acetylgalactosamine (GalNAc) to induce high plasma clearance through the hepatocyte asialoglycoprotein (ASGP) receptor. A phase 1/2A doseranging study recruited 58 healthy volunteers assigning 28 to a single-dose cohort and 30 to a multiple-dose cohort (Table 1). ${ }^{110} \mathrm{Lp}$ (a) was decreased by $59 \%$ in the $10 \mathrm{mg}$ group, $72 \%$ in the $20 \mathrm{mg}$ group, and $72 \%$ in the $40 \mathrm{mg}$ group at day 36 . No serious adverse events were recorded, and no injection site reactions, bleeds, or changes in liver parameters were seen.

The phase 2 study of pelacarsen (ISIS 681257 now AKCEA-APO(a)-LRx; TQJ230) in 286 patients with CVD and $\mathrm{Lp}(\mathrm{a})>60 \mathrm{mg} / \mathrm{dL}(127 \mathrm{nmol} / \mathrm{L})$, divided them into 5 cohorts and a placebo group. ${ }^{111}$ At 6 months, the $20 \mathrm{mg} / 4$ weeks group showed a decrease in $\mathrm{Lp}$ (a) of $35 \%$; $40 \mathrm{mg} / 4$ weeks achieved $56 \%$; $60 \mathrm{mg} / 4$ weeks $72 \%$; while $20 \mathrm{mg} / 2$ weeks reduced $\mathrm{Lp}$ (a) by $58 \%$; and $20 \mathrm{mg} /$ week $80 \%$. The most frequent adverse event was an injection site reaction that occurred in $26 \%$ of individuals.

Other siRNA-based therapies (ARC-LPa as known as AMG890 and SLN360) targeting LPA RNA are also in early development. These have just started phase 1 and 2 studies in man. ${ }^{112}$ Structural work on the binding properties of Kringle domains has led to the development of AZ005 which inhibits the function of K-IV10 domain and this small molecule inhibitor may proceed to human trials. ${ }^{113}$

\section{Cardiovascular Outcome Studies for Lp(a)}

All therapies licensed to date either have minimal effects on $\mathrm{Lp}$ (a) or have multiple actions on other parts of the lipid profile including LDL-C (PCSK-9 inhibitors); triglycerides and HDL-C (niacin). The development of specific therapies for $L p(a)$ means it is now possible to investigate whether intervention specifically on this risk factor will translate into clinical benefits. The first question that needs to be addressed is how to deliver sufficient statistical power to answer the question. Data from HPS-THRIVE suggested that $\mathrm{Lp}$ (a) reductions were predicted to reduce CAD risk by $\approx 2 \%$ overall and $6 \%$ in the top quintile by $\mathrm{Lp}$ (a) levels, so new therapies needed to reduce $\mathrm{Lp}$ (a) levels by $>80 \mathrm{nmol} / \mathrm{L}$ to produce worthwhile benefits. ${ }^{90} \mathrm{~A}$ Mendelian randomization study showed that a $102 \mathrm{mg} / \mathrm{dl}(\approx 260 \mathrm{nmol} / \mathrm{L})$ reduction would reproduce the effects seen with a $1 \mathrm{mmol} / \mathrm{L}$ reduction in LDL-C based on a $10 \mathrm{mg} / \mathrm{dl}(\approx 25 \mathrm{nmol} / \mathrm{L})$ translating to a $6 \%$ reduction in CVD events using a genetic risk score. ${ }^{49}$ Patients with $\mathrm{Lp}$ (a) levels $>100 \mathrm{nmol} / \mathrm{L}$ account for $5.7 \%$ of CVD events in the UK Biobank cohort, so recruiting patients with $\mathrm{CVD}$ and $\mathrm{Lp}$ (a) $>175 \mathrm{nmol} / \mathrm{L}$ may reduce CVD risk by $20 \%$, assuming causality, if the intervention reduces $\mathrm{Lp}$ (a) by $80 \% .{ }^{114}$

The second question is whether the effects of LDL-C and Lp(a) on CVD outcomes are independent. Data from observational studies suggest that Lp(a) may not have a significant effect in driving CVD risk if LDL$\mathrm{C}<2 \mathrm{mmol} / \mathrm{L} .{ }^{115}$ Data from a study of 2769 patients with possible CVD who had coronary angiography with $\mathrm{Lp}(\mathrm{a})$ $16 \mathrm{mg} / \mathrm{dl}$ (>30 mg/dl in 38\%) showed elevated Lp(a) was associated with a $2.3(1.7-3.2)$ fold likelihood of significant angiographic stenosis $(\mathrm{P}<0.001)$ and $1.5(1.3-1.7)$ fold chance of 3-vessel disease. $\mathrm{Lp}$ (a) levels were related to CVD outcomes in patients with LDL-C $70-100 \mathrm{mg} / \mathrm{dl}$ $(1.8-2.4 \mathrm{mmol} / \mathrm{L}) \quad(\mathrm{P}=0.05)$ and $>100 \mathrm{mg} / \mathrm{dl}(2.4 \mathrm{mmol} / \mathrm{L})$ $(\mathrm{P}=0.02)$, but not in those with LDL-C $<70 \mathrm{mg} / \mathrm{dl}$ $(1.8 \mathrm{mmol} / \mathrm{L})(\mathrm{p}=0.77) .{ }^{115}$ Current guidelines all suggest that patients with established CVD should attain LDL$\mathrm{C}<2 \mathrm{mmol} / \mathrm{L}^{70}$ (or be on highest dose of potent statin likely to have similar effects). ${ }^{116}$ Yet recent studies in patients with acute coronary syndromes with ezetimibe and PCSK9 inhibitors showed that LDL-C $1.6 \mathrm{mmol} / \mathrm{L}$ was attained with ezetimibe ${ }^{117}$ and $0.9 \mathrm{mmol} / \mathrm{L}$ with PCSK9 inhibitors ${ }^{118,119}$ with further benefits in CVD outcomes. This has led the ESC to suggest a target LDL-C of 1.4 $\mathrm{mmol} / \mathrm{L} .{ }^{68}$ Whether and to what extent $\mathrm{Lp}$ (a) will remain a significant risk factor in many patients after attainment of such low LDL-C remains unclear.

A CVD outcomes trial is underway with an $\mathrm{Lp}(\mathrm{a})$ reducing therapy (https://clinicaltrials.gov/ct2/show/ NCT04023552). The trial aims to recruit 7680 patients with established CVD, likely a treated LDL-C $<2 \mathrm{mmol} /$ 
$\mathrm{L}$, and an $\mathrm{Lp}(\mathrm{a})>70 \mathrm{mg} / \mathrm{dl}(\approx 175 \mathrm{nmol} / \mathrm{L})$. Patients had to have had a CHD or CVA event within 0.25-10yrs or have PAD. The trial is designed for a follow-up of 4 yrs. A prespecified analysis will also be conducted in patients with $\mathrm{Lp}(\mathrm{a})>90 \mathrm{mg} / \mathrm{dL}$.

\section{Conclusion}

Assessment of Lp(a) levels may be useful, yet standardized measurement of $\mathrm{Lp}$ (a) concentrations remains a challenge which restricts and complicates inferences made across studies, intervention trials, and the usefulness of measurement in routine clinical practice. There is a clear consensus that elevated Lp(a) levels are associated with increased risk of CVD events and may aid reclassification or review intervals. However, detailed health economic based policy recommendations for identifying exact threshold levels and which high-risk subgroups should be targeted or screened, remain to be developed. ${ }^{44}$ Recent CVD epidemiology previously showed enthusiasm for homocysteine measurement which had similar evidence for reclassification, but clinical trials failed to show any benefit on intervention. Modern lipid management of CVD is becoming more aggressive and targeting lower LDL-C levels. Whether reducing Lp(a) has any role once LDL-C has been optimally controlled, remains unclear. The results of ongoing intervention trials which target $\mathrm{Lp}$ (a) reduction with concomitant effects on other lipid sub-fractions, are eagerly awaited. These trials will help clarify the role of $\mathrm{Lp}(\mathrm{a})$ in atherosclerotic CVD.

\section{Disclosure}

Dr Adie Viljoen reports personal fees, non-financial support from Novo Nordisk, personal fees from Novartis, nonfinancial support from Lilly, personal fees from Boehringer Ingelheim, grants, personal fees from Sanofi, personal fees from Napp, personal fees from Novartis, personal fees from Pfizer, personal fees, non-financial support from Astra Zeneca, outside the submitted work. Professor Anthony S Wierzbicki is: Site clinical trial investigator: volanesorsen for Akcea, Site clinical trial investigator: Evinacumab for Regeneron, Site clinical trial investigator: Evolocumab for Amgen, outside the submitted work. The authors report no other conflicts in this work.

\section{References}

1. Scanu AM, Nakajima K, Edelstein C. Apolipoprotein(a): structure and biology. Front Biosci. 2001;6:D546-D554.
2. Schmidt K, Noureen A, Kronenberg F, Utermann G. Structure, function, and genetics of lipoprotein (a). J Lipid Res. 2016;57 (8):1339-1359. doi:10.1194/jlr.R067314

3. Utermann G, Weber W. Protein composition of Lp(a) lipoprotein from human plasma. FEBS Lett. 1983;154(2):357-361. doi:10.1016/0014-5793(83)80182-3

4. Utermann G, Menzel HJ, Kraft HG, Duba HC, Kemmler HG, Seitz C. Lp(a) glycoprotein phenotypes. Inheritance and relation to $\mathrm{Lp}(\mathrm{a})$-lipoprotein concentrations in plasma. JClinInvest. 1987;80(2):458-465. doi:10.1172/JCI113093

5. Utermann G, Kraft HG, Menzel HJ, Hopferwieser T, Seitz C. Genetics of the quantitative $\mathrm{Lp}$ (a) lipoprotein trait. I. Relation of $\mathrm{LP}$ (a) glycoprotein phenotypes to $\mathrm{Lp}$ (a) lipoprotein concentrations in plasma. Hum Genet. 1988;78(1):41-46.

6. Utermann G, Duba C, Menzel HJ. Genetics of the quantitative $\mathrm{Lp}$ (a) lipoprotein trait. II. Inheritance of $\mathrm{Lp}$ (a) glycoprotein phenotypes. Hum Genet. 1988;78(1):47-50.

7. Sandholzer C, Hallman DM, Saha N, et al. Effects of the apolipoprotein(a) size polymorphism on the lipoprotein(a) concentration in 7 ethnic groups. Hum Genet. 1991;86(6):607-614.

8. Lackner C, Boerwinkle E, Leffert CC, Rahmig T, Hobbs HH. Molecular basis of apolipoprotein (a) isoform size heterogeneity as revealed by pulsed-field gel electrophoresis. $J$ Clin Invest. 1991;87(6):2153-2161. doi:10.1172/JCI115248

9. Scanu AM. Lipoprotein(a). Link between structure and pathology. Ann Epidemiol. 1992;2(4):407-412.

10. Kamstrup PR, Tybjaerg-Hansen A, Steffensen R, Nordestgaard BG. Pentanucleotide repeat polymorphism, lipoprotein(a) levels, and risk of ischemic heart disease. J Clin Endocrinol Metab. 2008;93 (10):3769-3776. doi:10.1210/jc.2008-0830

11. Nordestgaard BG, Chapman MJ, Ray K, et al. Lipoprotein(a) as a cardiovascular risk factor: current status. Eur Heart J. 2010;31 (23):2844-2853. doi:10.1093/eurheartj/ehq386

12. Nordestgaard BG, Langsted A. Lipoprotein (a) as a cause of cardiovascular disease: insights from epidemiology, genetics, and biology. J Lipid Res. 2016;57(11):1953-1975. doi:10.1194/jlr.R071233

13. Clarke R, Peden JF, Hopewell JC, et al. Genetic variants associated with Lp(a) lipoprotein level and coronary disease. $N$ Engl J Med. 2009;361(26):2518-2528. doi:10.1056/NEJMoa0902604

14. Paquette M, Bernard S, Baass A. SLC22A3 is associated with lipoprotein (a) concentration and cardiovascular disease in familial hypercholesterolemia. Clin Biochem. 2019;66:44-48. doi:10.1016/j.clinbiochem.2019.02.008

15. Trinder M, Uddin MM, Finneran $P$, Aragam KG, Natarajan $P$. Clinical utility of Lipoprotein(a) and LPA genetic risk score in risk prediction of incident atherosclerotic cardiovascular disease. JAMA Cardiol. 2020;6(3):287-295. doi:10.1001/jamacardio.2020.5398

16. Bourgeois R, Girard A, Perrot N, et al. A comparative analysis of the Lipoprotein(a) and low-density lipoprotein proteomic profiles combining mass spectrometry and Mendelian randomization. CJC Open. 2021;3(4):450-459. doi:10.1016/j.cjco.2020.11.019

17. Hoekstra M, Chen HY, Rong J, et al. Genome-wide association study highlights APOH as a novel locus for Lipoprotein(a) levels-brief report. Arterioscler Thromb Vasc Biol. 2021;41 (1):458-464. doi:10.1161/ATVBAHA.120.314965

18. Frischmann ME, Ikewaki $\mathrm{K}$, Trenkwalder $\mathrm{E}$, et al. In vivo stable-isotope kinetic study suggests intracellular assembly of lipoprotein(a). Atherosclerosis. 2012;225(2):322-327. doi:10.10 16/j.atherosclerosis.2012.09.031

19. Becker L, Nesheim ME, Koschinsky ML. Catalysis of covalent $\mathrm{Lp}$ (a) assembly: evidence for an extracellular enzyme activity that enhances disulfide bond formation. Biochemistry. 2006;45 (32):9919-9928. doi:10.1021/bi060283t

20. Koschinsky ML, Marcovina SM. Structure-function relationships in apolipoprotein(a): insights into lipoprotein(a) assembly and pathogenicity. Curr Opin Lipidol. 2004;15(2):167-174. 
21. Hoppichler F, Kraft HG, Sandholzer C, Lechleitner M, Patsch JR, Utermann G. Lipoprotein(a) is increased in triglyceride-rich lipoproteins in men with coronary heart disease, but does not change acutely following oral fat ingestion. Atherosclerosis. 1996;122 (1):127-134. doi:10.1016/0021-9150(96)05803-0

22. Moriarty PM, Varvel SA, Gordts PL, McConnell JP, Tsimikas S. Lipoprotein(a) mass levels increase significantly according to APOE genotype: an analysis of 431,239 patients. Arterioscler Thromb Vasc Biol. 2017;37(3):580-588. doi:10.1161/ATVBAHA. 116.308704

23. McCormick SPA, Schneider WJ. Lipoprotein(a) catabolism: a case of multiple receptors. Pathology. 2019;51(2):155-164. doi:10.1016/j.pathol.2018.11.003

24. Tsimikas S. A test in context: lipoprotein(a): diagnosis, prognosis, controversies, and emerging therapies. $\mathrm{J}$ Am Coll Cardiol. 2017;69(6):692-711. doi:10.1016/j.jacc.2016.11.042

25. Boffa MB, Koschinsky ML. Lipoprotein (a): truly a direct prothrombotic factor in cardiovascular disease? J Lipid Res. 2016;57 (5):745-757. doi:10.1194/jlr.R060582

26. Tsimikas S. Lipoprotein(a): novel target and emergence of novel therapies to lower cardiovascular disease risk. Curr Opin Endocrinol Diabetes Obes. 2016;23(2):157-164. doi:10.1097/ MED.0000000000000237

27. Edelstein C, Pfaffinger D, Hinman J, et al. Lysinephosphatidylcholine adducts in kringle $\mathrm{V}$ impart unique immunological and potential pro-inflammatory properties to human apolipoprotein(a). J Biol Chem. 2003;278(52):52841-52847. doi:10.1074/jbc.M310425200

28. Berliner JA, Leitinger N, Tsimikas S. The role of oxidized phospholipids in atherosclerosis. J Lipid Res. 2009;50(Suppl):S20712. doi:10.1194/jlr.R800074-JLR200

29. Scipione CA, Sayegh SE, Romagnuolo R, et al. Mechanistic insights into Lp(a)-induced IL-8 expression: a role for oxidized phospholipid modification of apo(a). J Lipid Res. 2015;56 (12):2273-2285. doi:10.1194/jlr.M060210

30. van der Valk FM, Bekkering S, Kroon J, et al. Oxidized phospholipids on lipoprotein(a) elicit arterial wall inflammation and an inflammatory monocyte response in humans. Circulation. 2016;134 (8):611-624. doi:10.1161/CIRCULATIONAHA.116.020838

31. Tsimikas S, Clopton P, Brilakis ES, et al. Relationship of oxidized phospholipids on apolipoprotein B-100 particles to race/ethnicity, apolipoprotein(a) isoform size, and cardiovascular risk factors: results from the Dallas Heart Study. Circulation. 2009;119 (13):1711-1719. doi:10.1161/CIRCULATIONAHA.108.836940

32. Schwartz GG, Ballantyne CM, Barter PJ, et al. Association of lipoprotein(a) with risk of recurrent ischemic events following acute coronary syndrome: analysis of the dal-outcomes randomized clinical trial. JAMA Cardiol. 2018;3(2):164-168. doi:10.1001/jamacardio.2017.3833

33. Chan DC, Watts GF, Coll B, Wasserman SM, Marcovina SM, Barrett PHR. Lipoprotein(a) particle production as a determinant of plasma lipoprotein(a) concentration across varying apolipoprotein(a) isoform sizes and background cholesterol-lowering therapy. J Am Heart Assoc. 2019;8(7): e011781. doi:10.1161/JAHA.118.011781

34. Ma L, Waldmann E, Ooi EMM, et al. Lipoprotein (a) and Low-density lipoprotein apolipoprotein B metabolism following apheresis in patients with elevated lipoprotein(a) and coronary artery disease. Eur J Clin Invest. 2019;49(2):e13053. doi:10.1111/ eci. 13053

35. Croyal M, Blanchard V, Ouguerram K, et al. VLDL (Very-LowDensity Lipoprotein)-Apo E (Apolipoprotein E) may influence Lp(a) (lipoprotein [a]) synthesis or assembly. Arterioscler Thromb Vasc Biol. 2020;40(3):819-829. doi:10.1161/ ATVBAHA.119.313877
36. Mefford MT, Marcovina SM, Bittner V, et al. PCSK9 loss-offunction variants and $\mathrm{Lp}$ (a) phenotypes among black US adults. J Lipid Res. 2019;60(11):1946-1952. doi:10.1194/jlr.P119000173

37. Emerging Risk Factors Collaboration. Lipoprotein(a) concentration and the risk of coronary heart disease, stroke, and nonvascular mortality. JAMA. 2009;302(4):412-423. doi:10.1001/ jama.2009.1063.

38. Kamstrup PR, Tybjaerg-Hansen A, Steffensen R, Nordestgaard BG. Genetically elevated lipoprotein(a) and increased risk of myocardial infarction. JAMA. 2009;301 (22):2331-2339. doi:10.1001/jama.2009.801

39. Langsted A, Nordestgaard BG, Kamstrup PR. Elevated lipoprotein(a) and risk of ischemic stroke. $J$ Am Coll Cardiol. 2019;74(1):54-66. doi:10.1016/j.jacc.2019.03.524

40. Gurdasani D, Sjouke B, Tsimikas S, et al. Lipoprotein(a) and risk of coronary, cerebrovascular, and peripheral artery disease: the EPIC-Norfolk prospective population study. Arterioscler Thromb Vasc Biol. 2012;32(12):3058-3065. doi:10.1161/ATVBAHA.112. 255521

41. Langsted A, Kamstrup PR, Benn M, Tybjaerg-Hansen A, Nordestgaard BG. High lipoprotein(a) as a possible cause of clinical familial hypercholesterolaemia: a prospective cohort study. Lancet Diabetes Endocrinol. 2016;4(7):577-587. doi:10. 1016/S2213-8587(16)30042-0

42. Wong ND, Cupples LA, Ostfeld AM, Levy D, Kannel WB. Risk factors for long-term coronary prognosis after initial myocardial infarction: the Framingham Study. Am J Epidemiol. 1989;130 (3):469-480. doi:10.1093/oxfordjournals.aje.a115360

43. Wong ND, Zhao Y, Sung J, Browne A. Relation of first and total recurrent atherosclerotic cardiovascular disease events to increased lipoprotein(a) levels among statin treated adults with cardiovascular disease. Am $J$ Cardiol. 2021;145:12-17. doi:10.1016/j.amjcard.2020.12.075

44. Kostner KM, Kostner GM, Wierzbicki AS. Is Lp(a) ready for prime time use in the clinic? A pros-and-cons debate. Atherosclerosis. 2018;274:16-22. doi:10.1016/j.atherosclerosis.2018.04.032

45. Pare G, Caku A, McQueen M, et al. Lipoprotein(a) levels and the risk of myocardial infarction among 7 ethnic groups. Circulation. 2019;139(12):1472-1482. doi:10.1161/CIRCULATIONAHA.11 8.034311

46. Chretien JP, Coresh J, Berthier-Schaad Y, et al. Three single-nucleotide polymorphisms in LPA account for most of the increase in lipoprotein(a) level elevation in African Americans compared with European Americans. J Med Genet. 2006;43(12):917-923. doi:10.1136/jmg.2006.042119

47. Mehta A, Virani SS, Ayers CR, et al. Lipoprotein(a) and family history predict cardiovascular disease risk. J Am Coll Cardiol. 2020;76(7):781-793. doi:10.1016/j.jacc.2020.06.040

48. Ohira T, Schreiner PJ, Morrisett JD, Chambless LE, Rosamond WD, Folsom AR. Lipoprotein(a) and incident ischemic stroke: the Atherosclerosis Risk in Communities (ARIC) study. Stroke. 2006;37 (6):1407-1412. doi:10.1161/01.STR.0000222666.21482.b6

49. Burgess S, Ference BA, Staley JR, et al. Association of LPA variants with risk of coronary disease and the implications for lipoprotein(a)-lowering therapies: a Mendelian randomization analysis. JAMA Cardiol. 2018;3(7):619-627. doi:10.1001/ jamacardio.2018.1470

50. Huded CP, Shah NP, Puri R, et al. Association of serum lipoprotein (a) levels and coronary atheroma volume by intravascular ultrasound. J Am Heart Assoc. 2020;9(23):e018023. doi:10.1161/ JAHA.120.018023

51. Kamstrup PR, Tybjaerg-Hansen A, Nordestgaard BG. Elevated lipoprotein(a) and risk of aortic valve stenosis in the general population. J Am Coll Cardiol. 2014;63(5):470-477. doi:10.1016/j. jacc.2013.09.038 
52. Capoulade R, Chan KL, Yeang C, et al. Oxidized phospholipids, lipoprotein(a), and progression of calcific aortic valve stenosis. J Am Coll Cardiol. 2015;66(11):1236-1246. doi:10.1016/j.jacc. 2015.07.020

53. Zheng KH, Tsimikas S, Pawade $\mathrm{T}$, et al. Lipoprotein(a) and oxidized phospholipids promote valve calcification in patients with aortic stenosis. $J$ Am Coll Cardiol. 2019;73(17):21 50-2162. doi:10.1016/j.jacc.2019.01.070

54. Tsimikas S. Potential causality and emerging medical therapies for lipoprotein(a) and its associated oxidized phospholipids in calcific aortic valve stenosis. Circ Res. 2019;124(3):405-415. doi:10.1161/CIRCRESAHA.118.313864

55. Wierzbicki AS, Viljoen A, Chambers JB. Aortic stenosis and lipids: does intervention work? Curr Opin Cardiol. 2010;25 (4):379-384. doi:10.1097/HCO.0b013e3283393c9b

56. Garg PK, Guan W, Karger AB, Steffen BT, Budoff M, Tsai MY. Lipoprotein (a) and risk for calcification of the coronary arteries, mitral valve, and thoracic aorta: the multi-ethnic study of atherosclerosis. J Cardiovasc Comput Tomogr. 2021;15 (2):154-160. doi:10.1016/j.jcct.2020.06.002

57. Marcovina SM, Albers JJ. Lipoprotein (a) measurements for clinical application. J Lipid Res. 2016;57(4):526-537. doi:10.11 94/jlr.R061648

58. Tsimikas S, Fazio S, Ferdinand KC, et al. NHLBI working group recommendations to reduce lipoprotein(a)-mediated risk of cardiovascular disease and aortic stenosis. J Am Coll Cardiol. 2018;71 (2):177-192. doi:10.1016/j.jacc.2017.11.014

59. Moriarty PM, Yeang C, Varvel SA, McConnell JP, Tsimikas S. Removing the lipoprotein (a) from the LDL-C measurement results in a $38 \%$ reduction in prevalence of elevated LDL-C at any threshold: implications for the prevalence and diagnosis of LDL-mediated risk. $J$ Am Coll Cardiol. 2018;71(11):A1783. doi:10.1016/S0735-1097(18)32324-6

60. Seman LJ, DeLuca C, Jenner JL, et al. Lipoprotein(a)cholesterol and coronary heart disease in the Framingham Heart Study. Clin Chem. 1999;45(7):1039-1046. doi:10.1093/ clinchem/45.7.1039

61. Yeang C, Clopton PC, Tsimikas S. Lipoprotein(a)-cholesterol levels estimated by vertical auto profile correlate poorly with Lp(a) mass in hyperlipidemic subjects: implications for clinical practice interpretation of $\mathrm{Lp}(\mathrm{a})$-mediated risk. J Clin Lipidol. 2016;10(6):1389-1396. doi:10.1016/j.jacl.2016.09.012

62. Konerman M, Kulkarni K, Toth PP, Jones SR. Lipoprotein(a) particle concentration and lipoprotein(a) cholesterol assays yield discordant classification of patients into four physiologically discrete groups. J Clin Lipidol. 2012;6(4):368-373. doi:10.1016/j. jacl.2012.01.004

63. Guadagno PA, Summers Bellin EG, Harris WS, et al. Validation of a lipoprotein(a) particle concentration assay by quantitative lipoprotein immunofixation electrophoresis. Clin Chim Acta. 2015;439:219-224. doi:10.1016/j.cca.2014.10.013

64. Lamon-Fava S, Marcovina SM, Albers JJ, et al. Lipoprotein(a) levels, apo(a) isoform size, and coronary heart disease risk in the Framingham Offspring Study. J Lipid Res. 2011;52 (6):1181-1187. doi:10.1194/jlr.M012526

65. Yeang C, Witztum JL, Tsimikas S. Novel method for quantification of lipoprotein(a)-cholesterol: implications for improving accuracy of LDL-C measurements. J Lipid Res. 2021;62: 100053. doi:10.1016/j.jlr.2021.100053

66. Fatica EM, Meeusen JW, Vasile VC, Jaffe AS, Donato LJ. Measuring the contribution of $\mathrm{Lp}$ (a) cholesterol towards LDL-C interpretation. Clin Biochem. 2020;86:45-51. doi:10.1016/j. clinbiochem.2020.09.007
67. Nordestgaard BG, Langlois MR, Langsted A, et al. Quantifying atherogenic lipoproteins for lipid-lowering strategies: consensus-based recommendations from EAS and EFLM. Atherosclerosis. 2020;294:46-61. doi:10.1016/j.atherosclerosis. 20 19.12.005

68. Mach F, Baigent C, Catapano AL, et al. 2019 ESC/EAS Guidelines for the management of dyslipidaemias: lipid modification to reduce cardiovascular risk. Eur Heart J. 2019;41 (1):111-188. doi:10.1093/eurheartj/ehz455

69. Wilson DP, Jacobson TA, Jones PH, et al. Use of Lipoprotein(a) in clinical practice: a biomarker whose time has come. A scientific statement from the National Lipid Association. J Clin Lipidol. 2019;13(3):374-392. doi:10.1016/j.jacl.2019.04.010

70. Grundy SM, Stone NJ, Bailey AL, et al. $2018 \mathrm{AHA} / \mathrm{ACC} /$ AACVPR/AAPA/ABC/ACPM/ADA/AGS/APhA/ASPC/NLA/ PCNA guideline on the management of blood cholesterol: a report of the American College of Cardiology/American Heart Association Task Force on clinical practice guidelines. Circulation. 2019;139(25):e1082-e1143. doi:10.1161/CIR.0000 000000000625

71. Cegla J, Neely RDG, France M, et al. HEART UK consensus statement on Lipoprotein(a): a call to action. Atherosclerosis. 2019;291:62-70. doi:10.1016/j.atherosclerosis.2019.10.011

72. Gencer B, Kronenberg F, Stroes ES, Mach F. Lipoprotein(a): the revenant. Eur Heart J. 2017;38(20):1553-1560. doi:10.1093/eurheartj/ehx033

73. Varvel S, McConnell JP, Tsimikas S. Prevalence of elevated Lp(a) mass levels and patient thresholds in 532,359 patients in the United States. Arterioscler Thromb Vasc Biol. 2016;36 (11):2239-2245. doi:10.1161/ATVBAHA.116.308011

74. Kronenberg F. Human genetics and the causal role of lipoprotein(a) for various diseases. Cardiovasc Drugs Ther. 2016;30 (1):87-100. doi:10.1007/s10557-016-6648-3

75. Franchini M, Capuzzo E, Liumbruno GM. Lipoprotein apheresis for the treatment of elevated circulating levels of lipoprotein(a): a critical literature review. Blood Transfus. 2016;14(5):413-418. doi:10.2450/2015.0163-15

76. Roeseler E, Julius U, Heigl F, et al. Lipoprotein apheresis for lipoprotein(a)-associated cardiovascular disease: prospective 5 years of follow-up and apolipoprotein(a) characterization. Arterioscler Thromb Vasc Biol. 2016;36(9):2019-2027. doi:10. 1161/ATVBAHA.116.307983

77. Safarova MS, Ezhov MV, Afanasieva OI, et al. Effect of specific lipoprotein(a) apheresis on coronary atherosclerosis regression assessed by quantitative coronary angiography. Atheroscler Suppl. 2013;14(1):93-99. doi:10.1016/j.atherosclerosissup.2012.10.015

78. Wang X, Li J, Ju J, Fan Y, Xu H. Effect of different types and dosages of statins on plasma lipoprotein(a) levels: a network meta-analysis. Pharmacol Res. 2021;163:105275. doi:10.1016/j. phrs.2020.105275

79. Tsimikas S, Gordts P, Nora C, Yeang C, Witztum JL. Statin therapy increases lipoprotein(a) levels. Eur Heart J. 2020;41 (24):2275-2284. doi:10.1093/eurheartj/ehz310

80. Khera AV, Everett BM, Caulfield MP, et al. Lipoprotein(a) concentrations, rosuvastatin therapy, and residual vascular risk: an analysis from the JUPITER trial (Justification for the Use of Statins in Prevention: an Intervention Trial Evaluating Rosuvastatin). Circulation. 2014;129(6):635-642. doi:10.1161/ CIRCULATIONAHA.113.004406

81. Sahebkar A, Simental-Mendia LE, Watts GF, et al. Comparison of the effects of fibrates versus statins on plasma lipoprotein(a) concentrations: a systematic review and meta-analysis of head-tohead randomized controlled trials. BMC Med. 2017;15(1):22. doi:10.1186/s12916-017-0787-7 
82. Sahebkar A, Simental-Mendia LE, Pirro M, et al. Impact of ezetimibe on plasma lipoprotein(a) concentrations as monotherapy or in combination with statins: a systematic review and meta-analysis of randomized controlled trials. Sci Rep. 2018;8 (1):17887. doi:10.1038/s41598-018-36204-7

83. Schaefer EJ, Lamon-Fava S, Jenner JL, et al. Lipoprotein(a) levels and risk of coronary heart disease in men. The lipid research clinics coronary primary prevention trial. JAMA. 1994;271(13):999-1003. doi:10.1001/jama.1994.03510370051031

84. Wang X, Luo S, Gan X, He C, Huang R. Safety and efficacy of ETC-1002 in hypercholesterolaemic patients: a meta-analysis of randomised controlled trials. Kardiol Pol. 2019;77(2):207-216. doi:10.5603/KP.a2019.0013

85. Sahebkar A, Reiner Z, Simental-Mendia LE, Ferretti G, Cicero AF. Effect of extended-release niacin on plasma lipoprotein(a) levels: a systematic review and meta-analysis of randomized placebo-controlled trials. Metabolism. 2016;65 (11):1664-1678. doi:10.1016/j.metabol.2016.08.007

86. Croyal M, Ouguerram K, Passard M, et al. Effects of extended-release nicotinic acid on apolipoprotein (a) kinetics in hypertriglyceridemic patients. Arterioscler Thromb Vasc Biol. 2015;35(9):2042-2047. doi:10.1161/ATVBAHA.115.305835

87. Taylor AJ, Sullenberger LE, Lee HJ, Lee JK, Grace KA. Arterial Biology for the Investigation of the Treatment Effects of Reducing Cholesterol (ARBITER) 2: a double-blind, placebo-controlled study of extended-release niacin on atherosclerosis progression in secondary prevention patients treated with statins. Circulation. 2004;110 (23):3512-3517. doi:10.1161/01.CIR.0000148955.19792.8D

88. Boden WE, Probstfield JL, Anderson T, et al. Niacin in patients with low HDL cholesterol levels receiving intensive statin therapy. N Engl J Med. 2011;365(24):2255-2267. doi:10.1056/ NEJMoa1107579

89. HPS THRIVE Collaborative Group. Effects of extended-release niacin with laropiprant in high-risk patients. $N$ Engl J Med. 2014;371(3):203-212. doi:10.1056/NEJMoa1300955.

90. Parish S, Hopewell JC, Hill MR, et al. Impact of apolipoprotein(a) isoform size on lipoprotein(a) lowering in the HPS2-THRIVE study. Circ Genom Precis Med. 2018;11(2):e001696. doi:10.1161/ CIRCGEN.117.001696

91. Farmakis I, Doundoulakis I, Pagiantza A, et al. Lipoprotein(a) reduction with proprotein convertase subtilisin/kexin type 9 inhibitors: a systematic review and meta-analysis. J Cardiovasc Pharmacol. 2021;77(3):397-407. doi:10.1097/FJC.0000000000000963

92. Watts GF, Chan DC, Somaratne R, et al. Controlled study of the effect of proprotein convertase subtilisin-kexin type 9 inhibition with evolocumab on lipoprotein(a) particle kinetics. Eur Heart J. 2018;39:2577-2585. doi:10.1093/eurheartj/ehy122

93. O’Donoghue ML, Fazio S, Giugliano RP, et al. Lipoprotein(a), PCSK9 inhibition, and cardiovascular risk. Circulation. 2019;139 (12):1483-1492. doi:10.1161/CIRCULATIONAHA.118.037184

94. Ruscica M, Greco MF, Ferri N, Corsini A. Lipoprotein(a) and PCSK9 inhibition: clinical evidence. Eur Heart J. 2020;22 (SupplL):L53-L56. doi:10.1093/eurheartj/suaa135

95. Shapiro MD, Minnier J, Tavori H, et al. Relationship between low-density lipoprotein cholesterol and lipoprotein(a) lowering in response to PCSK9 inhibition with evolocumab. J Am Heart Assoc. 2019;8(4):e010932. doi:10.1161/JAHA.118.010932

96. Bittner VA, Szarek M, Aylward PE, et al. Effect of alirocumab on lipoprotein(a) and cardiovascular risk after acute coronary syndrome. $J$ Am Coll Cardiol. 2020;75(2):133-144. doi:10.1016/j.jacc.2019.10.057

97. Szarek M, Bittner VA, Aylward P, et al. Lipoprotein(a) lowering by alirocumab reduces the total burden of cardiovascular events independent of low-density lipoprotein cholesterol lowering: ODYSSEY OUTCOMES trial. Eur Heart J. 2020;41 (44):4245-4255. doi:10.1093/eurheartj/ehaa649
98. Mahmood T, Minnier J, Ito MK, et al. Discordant responses of plasma low-density lipoprotein cholesterol and lipoprotein(a) to alirocumab: a pooled analysis from 10 ODYSSEY phase 3 studies. Eur J Prev Cardiol. 2020;28(8):816-822. . doi:10.1177/ 2047487320915803.

99. Ray KK, Stoekenbroek RM, Kallend D, et al. Effect of an siRNA therapeutic targeting PCSK9 on atherogenic lipoproteins: prespecified secondary end points in ORION 1. Circulation. 2018;138 (13):1304-1316. doi:10.1161/CIRCULATIONAHA.118.034710

100. Fogacci F, Ferri N, Toth PP, Ruscica M, Corsini A, Cicero AFG. Efficacy and safety of mipomersen: a systematic review and meta-analysis of randomized clinical trials. Drugs. 2019;79 (7):751-766. doi:10.1007/s40265-019-01114-z

101. Santos RD, Raal FJ, Catapano AL, Witztum JL, SteinhagenThiessen E, Tsimikas S. Mipomersen, an antisense oligonucleotide to apolipoprotein B-100, reduces lipoprotein(a) in various populations with hypercholesterolemia: results of 4 phase III trials. Arterioscler Thromb Vasc Biol. 2015;35(3):689-699. doi:10.1161/ATVBAHA.114.304549

102. Nandakumar R, Matveyenko A, Thomas T, et al. Effects of mipomersen, an apolipoprotein B100 antisense, on lipoprotein (a) metabolism in healthy subjects. J Lipid Res. 2018;59 (12):2397-2402. doi:10.1194/jlr.P082834

103. Arsenault BJ, Petrides F, Tabet F, et al. Effect of atorvastatin, cholesterol ester transfer protein inhibition, and diabetes mellitus on circulating proprotein subtilisin kexin type 9 and lipoprotein(a) levels in patients at high cardiovascular risk. J Clin Lipidol. 2018;12(1):130-136. doi:10.1016/j.jacl.2017.10.001

104. Nicholls SJ, Ruotolo G, Brewer HB, et al. Evacetrapib alone or in combination with statins lowers lipoprotein(a) and total and small LDL particle concentrations in mildly hypercholesterolemic patients. J Clin Lipidol. 2016;10(3):519-527 e4. doi:10.1016/j. jacl.2015.11.014

105. Thomas T, Zhou H, Karmally W, et al. CETP (Cholesteryl Ester Transfer Protein) inhibition with anacetrapib decreases production of lipoprotein(a) in mildly hypercholesterolemic subjects. Arterioscler Thromb Vasc Biol. 2017;37(9):1770-1775. doi:10.1161/ATVBAHA.117.309549

106. Merki E, Graham MJ, Mullick AE, et al. Antisense oligonucleotide directed to human apolipoprotein B-100 reduces lipoprotein(a) levels and oxidized phospholipids on human apolipoprotein B-100 particles in lipoprotein(a) transgenic mice. Circulation. 2008;118 (7):743-753. doi:10.1161/CIRCULATIONAHA.108.786822

107. Graham MJ, Viney N, Crooke RM, Tsimikas S. Antisense inhibition of apolipoprotein (a) to lower plasma lipoprotein (a) levels in humans. J Lipid Res. 2016;57(3):340-351. doi:10.1194/jlr.R052258

108. Tsimikas S, Viney NJ, Hughes SG, et al. Antisense therapy targeting apolipoprotein(a): a randomised, double-blind, placebo-controlled phase 1 study. Lancet. 2015;386 (10002):1472-1483. doi:10.1016/S0140-6736(15)61252-1

109. Viney NJ, van Capelleveen JC, Geary RS, et al. Antisense oligonucleotides targeting apolipoprotein(a) in people with raised lipoprotein(a): two randomised, double-blind, placebo-controlled, dose-ranging trials. Lancet. 2016;388(10057):2239-2253. doi:10.1016/S0140-6736(16)31009-1

110. Tsimikas S, Karwatowska-Prokopczuk E, Gouni-Berthold I, et al. Safety and efficacy of AKCEA-APO(a)-LRx to lower lipoprotein(a) levels in patients with established cardiovascular disease: a phase 2 dose-ranging trial American Heart Association: scientific sessions 2018; 2021. Available from: https://www.abstractson line.com/pp8/\#!/4682/presentation/59761. Accessed June 1, 2021.

111. Tsimikas S, Karwatowska-Prokopczuk E, Gouni-Berthold I, et al. Lipoprotein(a) reduction in persons with cardiovascular disease. $N$ Engl J Med. 2020;382(3):244-255. doi:10.1056/NEJMoa19 05239 
112. Swerdlow DI, Rider DA, Yavari A, Lindholm MW, Campion GV, Nissen SE. Treatment and prevention of lipoprotein(a)-mediated cardiovascular disease: the emerging potential of RNA interference therapeutics. Cardiovasc Res. 2021;cvab100. doi:10.1093/ cvr/cvab100

113. Sandmark J, Tigerstrom A, Akerud T, et al. Identification and analyses of inhibitors targeting apolipoprotein(a) kringle domains KIV-7, KIV-10, and KV provide insight into kringle domain function. J Biol Chem. 2020;295(15):5136-5151. doi:10.1074/ jbc.RA119.011251

114. Welsh P, Welsh C, Celis-Morales CA, et al. Lipoprotein(a) and cardiovascular disease: prediction, attributable risk fraction, and estimating benefits from novel interventions. Eur J Prev Cardiol. 2020;zwaa063. doi:10.1093/eurjpc/zwaa063

115. Nicholls SJ, Tang WH, Scoffone H, et al. Lipoprotein(a) levels and long-term cardiovascular risk in the contemporary era of statin therapy. J Lipid Res. 2010;51(10):3055-3061. doi:10.1194/jlr.M008961
116. Rabar S, Harker M, O’Flynn N, Wierzbicki AS; Guideline Development Group. Lipid modification and cardiovascular risk assessment for the primary and secondary prevention of cardiovascular disease: summary of updated NICE guidance. BMJ. 2014;349:g4356. doi:10.1136/bmj.g4356.

117. Cannon CP, Blazing MA, Giugliano RP, et al. Ezetimibe added to statin therapy after acute coronary syndromes. $N$ Engl J Med. 2015;372(25):2387-2397. doi:10.1056/NEJMoa1410489

118. Sabatine MS, Giugliano RP, Keech AC, et al. Evolocumab and clinical outcomes in patients with cardiovascular disease. $N$ Engl $J$ Med. 2017;376(18):1713-1722. doi:10.1056/NEJMoa1615664

119. Schwartz GG, Steg PG, Szarek M, et al. Alirocumab and cardiovascular outcomes after acute coronary syndrome. N Engl J Med. 2018;379(22):2097-2107. doi:10.1056/NEJMoa1801174

\section{Publish your work in this journal}

Vascular Health and Risk Management is an international, peerreviewed journal of therapeutics and risk management, focusing on concise rapid reporting of clinical studies on the processes involved in the maintenance of vascular health; the monitoring, prevention and treatment of vascular disease and its sequelae; and the involvement of metabolic disorders, particularly diabetes. This journal is indexed on PubMed Central and MedLine. The manuscript management system is completely online and includes a very quick and fair peerreview system, which is all easy to use. Visit http://www.dovepress. com/testimonials.php to read real quotes from published authors. 